Supporting Information

\title{
Protein- Activatable Diarylethene Monomer as a Smart Trigger of Noninvasive Control Over Reversible Generation of Singlet Oxygen: \\ A Facile, Switchable, Theranostic Strategy for Photodynamic- Immunotherapy
}

\footnotetext{
Hong-Bo Cheng, ${ }^{*, 1 \#}$ Bin Qiao, ${ }^{3,4 \#} \mathrm{Hao} \mathrm{Li},{ }^{5 *} \mathrm{Jin} \mathrm{Cao}^{4}$, Yuanli Luo ${ }^{4}$, Kunemadihalli Mathada Kotraiah Swamy, ${ }^{2,6}$ Zhigang Wang, ${ }^{4}$ Jing Zhao, ${ }^{1}$ Jin Yong Lee, ${ }^{*, 5}$ Xing-Jie Liang, ${ }^{*, 3}$ Juyoung Yoon $*, 2$

${ }^{1}$ College of Materials Science and Engineering, Beijing University of Chemical Technology, 15 North Third Ring Road, Beijing 100029, P. R. China email: chenghb@mail.buct.edu.cn

2 Department of Chemistry and Nanoscience, Ewha Womans University, Seoul 120-750, Korea email: jyoon@ewha.ac.kr

${ }^{3}$ CAS Key Laboratory for Biomedical Effects of Nanomaterials and Nanosafety, CAS Center for Excellence in Nanoscience, National Center for Nanoscience and Technology of China, Beijing 100190, China email: liangxj@,nanoctr.cn

${ }^{4}$ The Second Affiliated Hospital of Chongqing Medical University, Chongqing 400010, China

${ }^{5}$ Department of Chemistry, Sungkyunkwan University, Suwon 16419, Korea email: jinylee@skku.edu

${ }^{6}$ Department of Pharmaceutical Chemistry, V. L. College of Pharmacy, RAICHUR-584 103,

Karnataka State, India
} 


\section{Materials and methods}

All reagents were used as received. 4-(2-(1,2-dimethyl-1H-indol-3-yl)-3,3,4,4,5,5hexafluorocyclopent-1-en-1-yl)-5-methylthiophene-2-carbaldehyde 2 was prepared according to the literature's procedure. ${ }^{[1]}$ Porphyrin with four sulfonic acid groups (TPPS) and 2-Bis(2,4-dimethyl-5-phenyl-3-thienyl)-3,3,4,4, 5,5-hexafluoro-1cyclopentene (BHC) are commercial reagents purchased from TCI corporation.

UV absorption spectra were obtained on a VIKON 933 Double Beam UV/VIS Spectrometer. Fluorescence emission spectra were obtained using a RF-5301/PC Spectro fluorophotometer (Shimadzu). ${ }^{1} \mathrm{H}$ NMR spectra were determined using a Bruker AVANCE III 400 spectrometer (400 MHz). High-resolution mass spectra (HRMS) were determined using an Exactive Plus Orbitrap (Thermo Fisher Scientific). Dynamic light scattering (DLS) was measured using a Nano-ZS (Malvern). TEM images were recorded on a JEOL-2100F electron microscope operating at $200 \mathrm{kV}$.

\section{Synthetic Protocols}

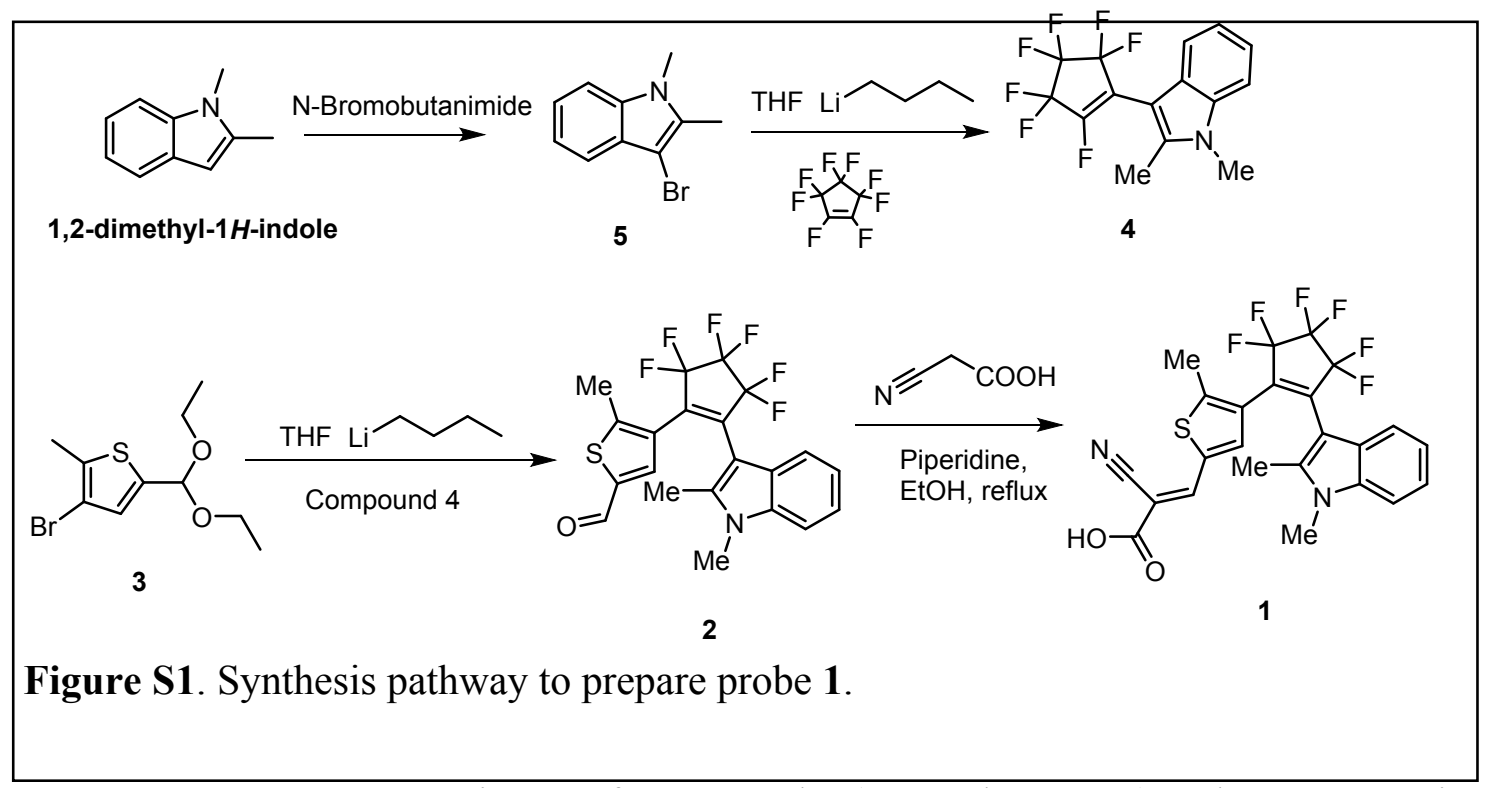

Synthesis of probe 1. A mixture of compound $2(1 \mathrm{mmol}, 443 \mathrm{mg})$ and 2-cyanoacetic acid $(2 \mathrm{mmol}, 170 \mathrm{mg})$ in anhydrous EtOH containing 2 drops piperidine was stirred at reflux overnight. The solvent was removed under reduced pressure, and the residue was subjected to silica column chromatography to form product $\mathbf{1}(260 \mathrm{mg}, 51 \%) .{ }^{1} \mathrm{H}$ NMR (400 MHz, DMSO) $\delta 8.09(\mathrm{~s}, 1 \mathrm{H}), 7.82(\mathrm{~s}, 1 \mathrm{H}), 7.51(\mathrm{~d}, J=8.2 \mathrm{~Hz}, 1 \mathrm{H}), 7.40(\mathrm{~d}, J=$ $8.1 \mathrm{~Hz}, 1 \mathrm{H}), 7.24-7.15(\mathrm{~m}, 1 \mathrm{H}), 7.14-7.05(\mathrm{~m}, 1 \mathrm{H}), 3.68(\mathrm{~s}, 3), 2.02(\mathrm{~s}, 3 \mathrm{H}), 1.78(\mathrm{~s}$, 
3H). HRMS (ESI) $\mathrm{m} / \mathrm{z}[\mathrm{M}+\mathrm{H}]^{+}$calcd for $\mathrm{C}_{24} \mathrm{H}_{17} \mathrm{~F}_{6} \mathrm{~N}_{2} \mathrm{O}_{2} \mathrm{~S}^{+} 511.0915$, found 511.09162.

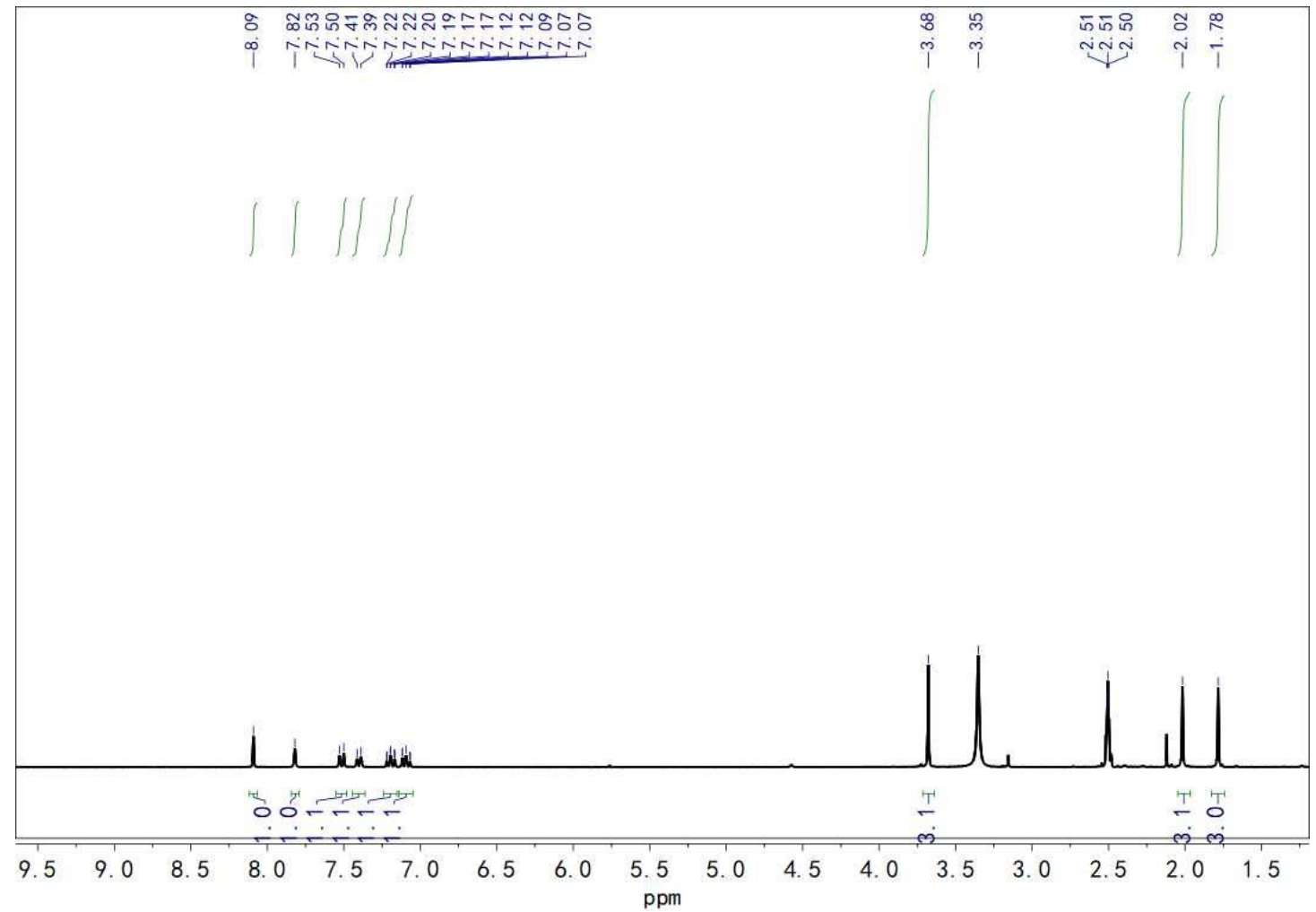

Figure S2. ${ }^{1} \mathrm{H}$ NMR spectrum of 1 (DMSO- $\left.D_{6}, 400 \mathrm{MHz}, 298 \mathrm{~K}\right)$.

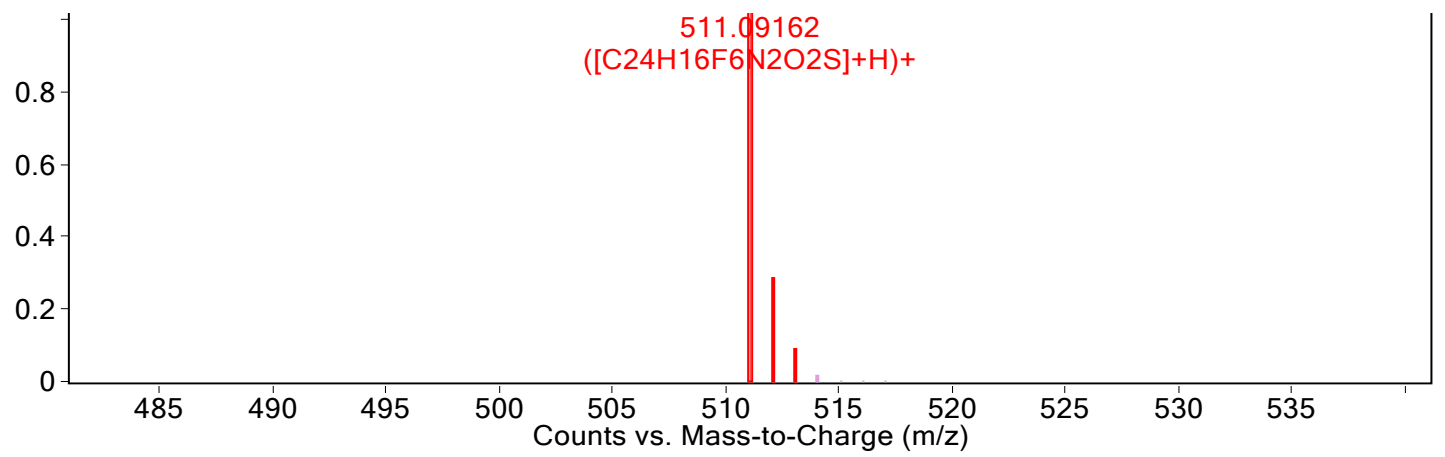

Figure S3. The HRMS spectrum of $\mathbf{1}$.

\section{Synthesis and Optimization of HSA-DIA-porphyrin Nanoparticles.}

HSA-DIA-porphyrin nanoparticles were prepared by a glutaraldehyde-induced covalent albumin cross-linking method following a literature protocol. Briefly, HSA, DIA and porphyrin was dissolved in $2 \mathrm{~mL}$ of water, into which $2 \mathrm{~mL}$ of ethanol was dropwisely added under stirring at a rate of $0.5 \mathrm{~mL} / \mathrm{min}$. To induce cross-linking of proteins, $14 \mu \mathrm{L}$ of $8 \%$ glutaraldehyde was added into the above solution, which was then stirred at room temperature for $12 \mathrm{~h}$. HSA-DIA-porphyrin nanoparticles were obtained after dialyzing these solutions against water to remove glutaraldehyde and 
ethanol and ultrafiltration by a centrifugal filter device $(\mathrm{MWCO}=100 \mathrm{kDa})$ three times to remove free HSA.

${ }^{1} \mathbf{O}_{2}$ Measurement. A xenon lamp (500W, BL Ltd.) with $420 \mathrm{~nm}$ pass filters (Power density $\sim 100 \mathrm{~mW} / \mathrm{cm}^{2}$ ) was applied to perform light irradiate. To monitor the production of ${ }^{1} \mathrm{O}_{2}$, singlet oxygen sensor green (SOSG) was employed as the indicator according to the provider's protocol. The C-NPs were irradiated by $365 \mathrm{~nm}$ UV light for $1.5 \mathrm{~min}$ to form O-NPs. For PDT, the SOSG solution was incubated with the solution of O-NPs and C-NPs $(10 \mu \mathrm{g} / \mathrm{mL})$, and then irradiated with $420 \mathrm{~nm}$ light (100 $\left.\mathrm{mW} / \mathrm{cm}^{2}\right)$ for different times. The solution was analyzed with fluorescence (Ex:504 nm, $\mathrm{Em}: 525 \mathrm{~nm})$.

Cell Culture. 4T1 cells (breast cancer cells) were incubated with RPMI-1640 medium containing $10 \%$ fetal bovine serum (FBS) and 1\% penicillin-streptomycin $(10,000$ $\mathrm{U} / \mathrm{mL}$ ) at $37^{\circ} \mathrm{C}$ in a humidified atmosphere containing $5 \% \mathrm{CO}_{2}$.

Confocal Laser Scanning Microscopy (CLSM) Evaluation. 4T1 cells were incubated with O-NPs and C-NPs $(40 \mu \mathrm{g} / \mathrm{mL})$ for $4 \mathrm{~h}$ and the medium was replaced with fresh RPMI-1640 containing $5 \mu \mathrm{M}$ of DCFH-DA for further incubation of $30 \mathrm{~min}$ in dark. A xenon lamp with a $420 \mathrm{~nm}$ pass filter $\left(100 \mathrm{~mW} / \mathrm{cm}^{2}\right)$ was used for $3 \mathrm{~min}$ irradiation to induce ROS production after repeated wash with fresh PBS $(0.01 \mathrm{M}, \mathrm{pH}$ $=7.4$ ). The fluorescence of DCF was observed by CLSM (ZEISS, LSM710).

In Vivo PDT Treatment and pathology analysis. All animal experiment protocols were conducted under the guidelines of the Institutional Animal Care and Use Committee of the National Center for Nanoscience and Technology. 6- to 8- weeks female BALB/c nude mice were purchased from the Beijing Charles River Company and raised in a specific pathogen-free grade laboratory. $100 \mu \mathrm{L}$ of cell suspension containing $5.0 \times 10^{6} 4 \mathrm{~T} 1$ cells were injected subcutaneously in the right flank region of the nude mice. When the size of tumor volume reached approximately $50 \mathrm{~mm}^{3}$, the mice were randomly divided into six groups ( $\mathrm{n}=5$ mice in each group). Mice were injected with O-NPs or C-NPs at a dose of $20 \mu \mathrm{M}(100 \mu \mathrm{L})$ for each group. PBS was set as a control. Besides, mice of control $+\mathrm{L}$ group, O-NPs $+\mathrm{L}$ group and C-NPs $+\mathrm{L}$ were treated with a $420 \mathrm{~nm}$ laser $\left(100 \mathrm{~mW} / \mathrm{cm}^{2}\right)$ for $30 \mathrm{~min}$ after the NPs was injected for $12 \mathrm{~h}$. PDT was performed every other day for a total of four injections/treatments. Tumor volume and body weight were measured every other day. The tumor volume was determined as length $\times$ width $^{2} / 2$ and the relative tumor volumes were calculated as $\mathrm{V} / \mathrm{V}_{0}\left(\mathrm{~V}_{0}\right.$ was the initial tumor volume during the treatment process). All mice were 
sacrificed on day 13 and the excised tumors were photographed and weighed. H\&E staining of major organs (including heart, liver, spleen, lungs, and kidneys) and tumors were performed to evaluate the toxicity and observed under an optical microscope.

Abscopal effect on 4T1 tumor-bearing mice: $100 \mu \mathrm{L}$ of cell suspension containing $5.0 \times 10^{6} 4 \mathrm{~T} 1$ cells were subcutaneously injected into the left flank region of Balb/c mice as the primary tumor. Six days later, 4T1 cells were subcutaneously injected into the right flank region as the second tumor. The mice were divided into five groups randomly, including (i) Control, (ii) O-NPs+L, (iii) aPD-L1, (iv) C-NPs+L+aPD-L1, (v) O-NPs $+\mathrm{L}+\mathrm{aPD}-\mathrm{L} 1$. When the primary tumors grew to approximately $50 \mathrm{~mm}^{3}, \mathrm{C}-$ NPs or O-NPs was injected into a mouse at a dose of $20 \mu \mathrm{M}(100 \mu \mathrm{L})$ for each group. PBS was set as a control. Besides, mice of O-NPs + L group and C-NPs + L were treated with a $420 \mathrm{~nm}$ laser $\left(100 \mathrm{~mW} / \mathrm{cm}^{2}\right)$ for $30 \mathrm{~min}$ after the NPs was injected for $12 \mathrm{~h}$. aPD-L1 antibodies at a dose of $60 \mu \mathrm{g}$ /mouse were administered on days 1,4 , and 6 . The mice with tumors exceeding $1000 \mathrm{~mm}^{3}$ were euthanized according to the standard animal protocols.

Mechanism investigation of the in vivo combined therapy: After different treatments, the mice were sacrificed. The distant tumors were collected and homogenized. The tumors derived from 4T1 tumors were harvested and treated with the tissue dissociation kit to produce a single-cell suspension according to the specific procedures. Briefly, the tumor samples were cut into $1 \mathrm{~mm}^{3}$ fragments and treated with collagenase IV (1 $\mathrm{mg} / \mathrm{mL})$ and DNase-I $(1 \mathrm{mg} / \mathrm{mL})$ in PBS solutions $(5 \mathrm{~mL})$. The samples were incubated at $37^{\circ} \mathrm{C}$ for $30 \mathrm{~min}$, grounded with a rubber end of a syringe, and filtered through 40 $\mu \mathrm{m}$ of the nylon mesh filter. The harvest cells were stained with several fluorochromeconjugated antibodies: CD45-APC-Cy7 (Biolegend, Catalog:103116), CD3-FITC (Biolegend, Catalog:551163), CD4-Percp (Biolegend, Catalog:100431), CD8-APC (Biolegend, Catalog:100711), live-dead-BV421 (Biolegend, Catalog:423114). IL-6 and IFN- $\gamma$ were analyzed with ELISA kits at $24 \mathrm{~h}$ after different treatments according to the corresponding instructions provided by the manufacturer. 


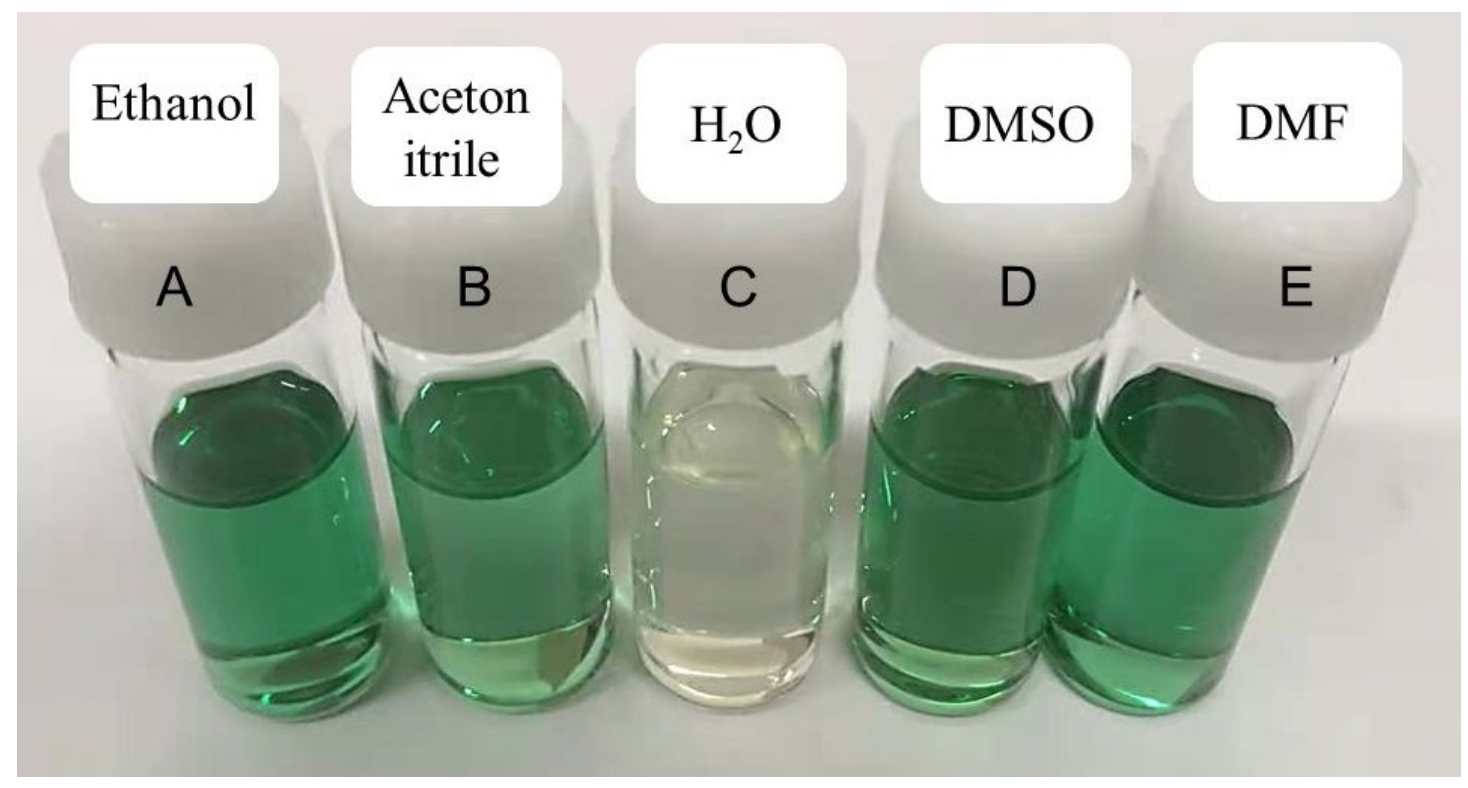

Figure $\mathbf{S 4}$ The picture of DIA $(30 \mu \mathrm{M})$ in (A) ethanol, (B) acetonitrile, (C) $\mathrm{H}_{2} \mathrm{O}$, (D) DMSO and (E) DMF after irradiation with $365 \mathrm{~nm}$.

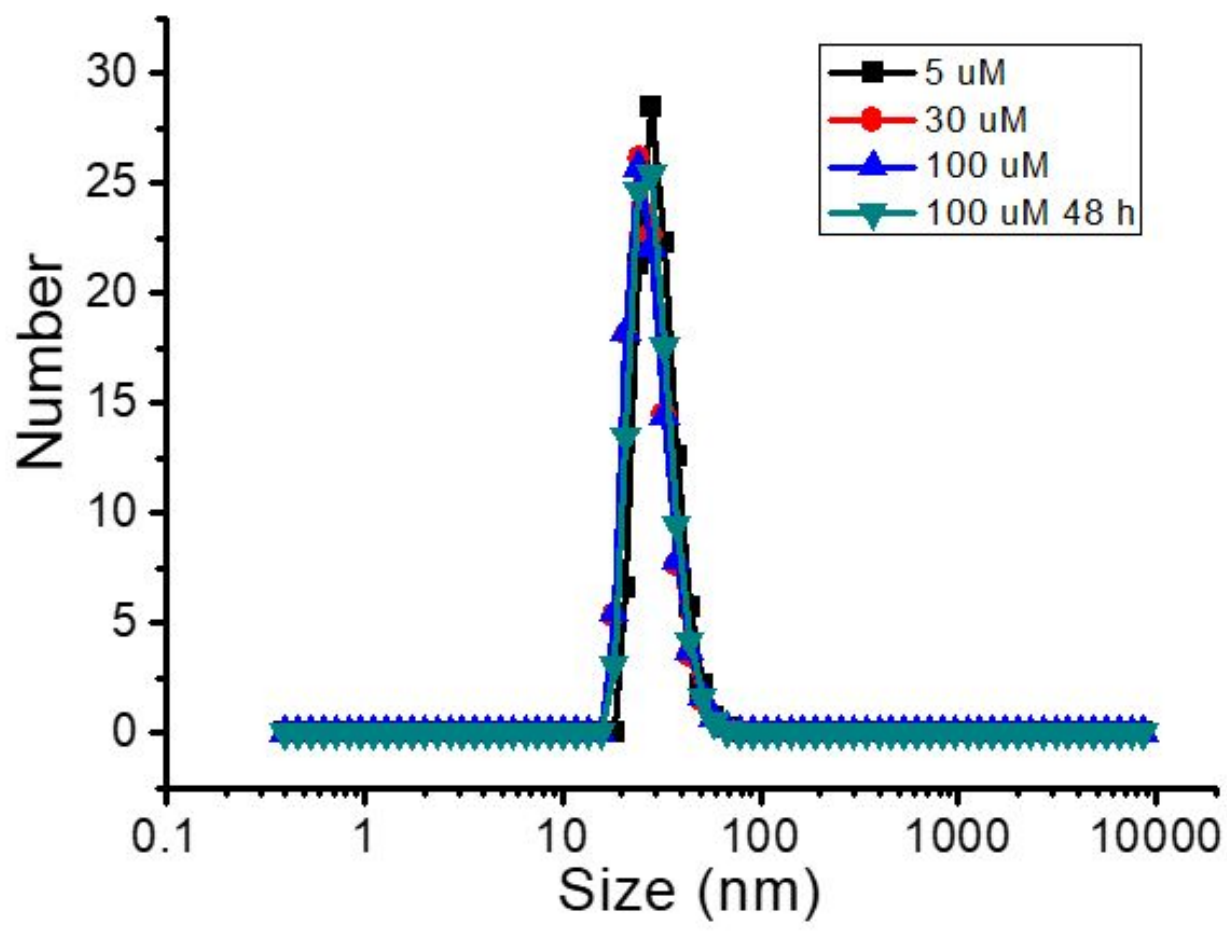

Figure S5. NanoDIA in the different concentration. 


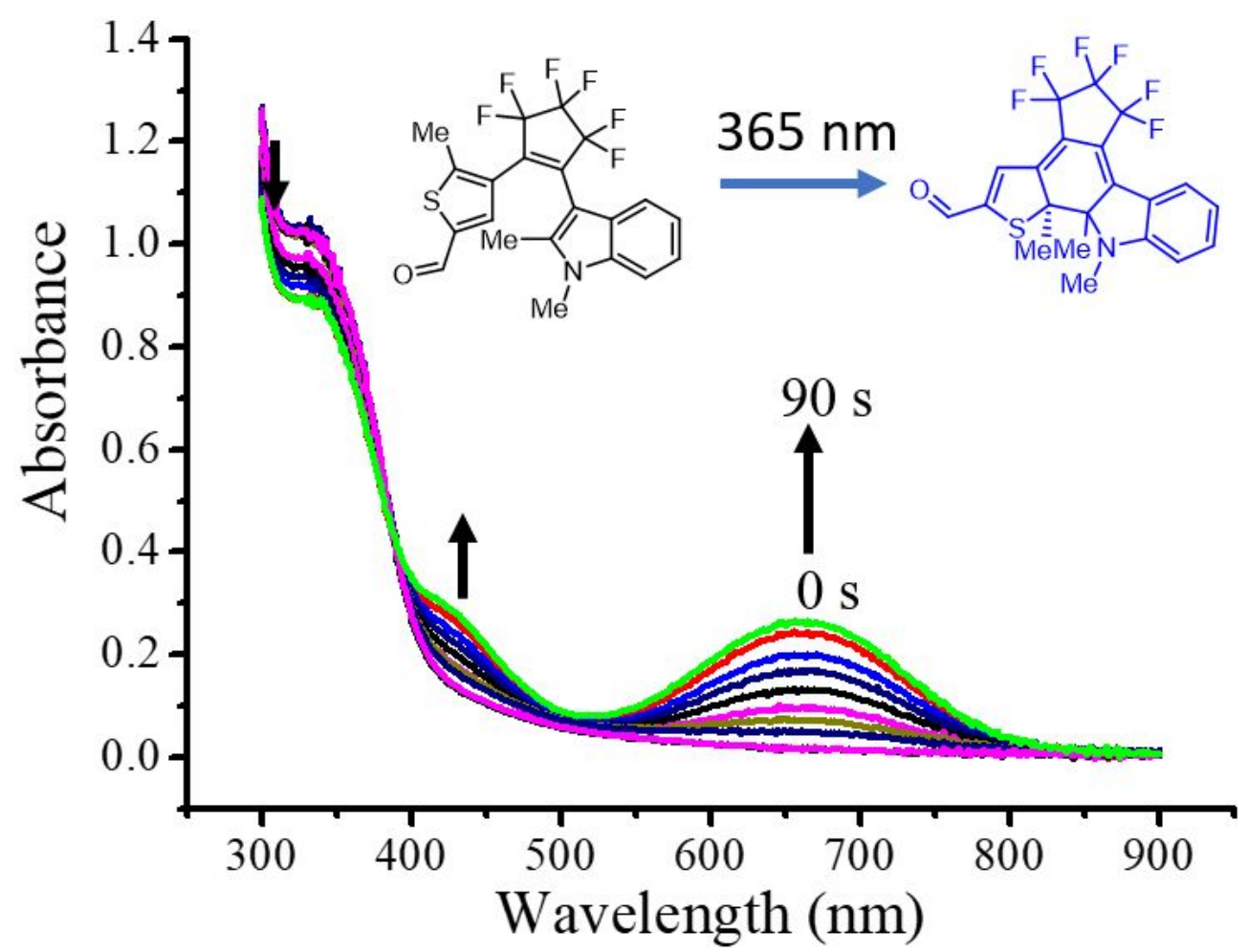

Figure S6. Absorption spectra of $2(20 \mu \mathrm{M})$ upon exposure to $365 \mathrm{~nm}$ light for 90 seconds in $\mathrm{H}_{2} \mathrm{O}$.

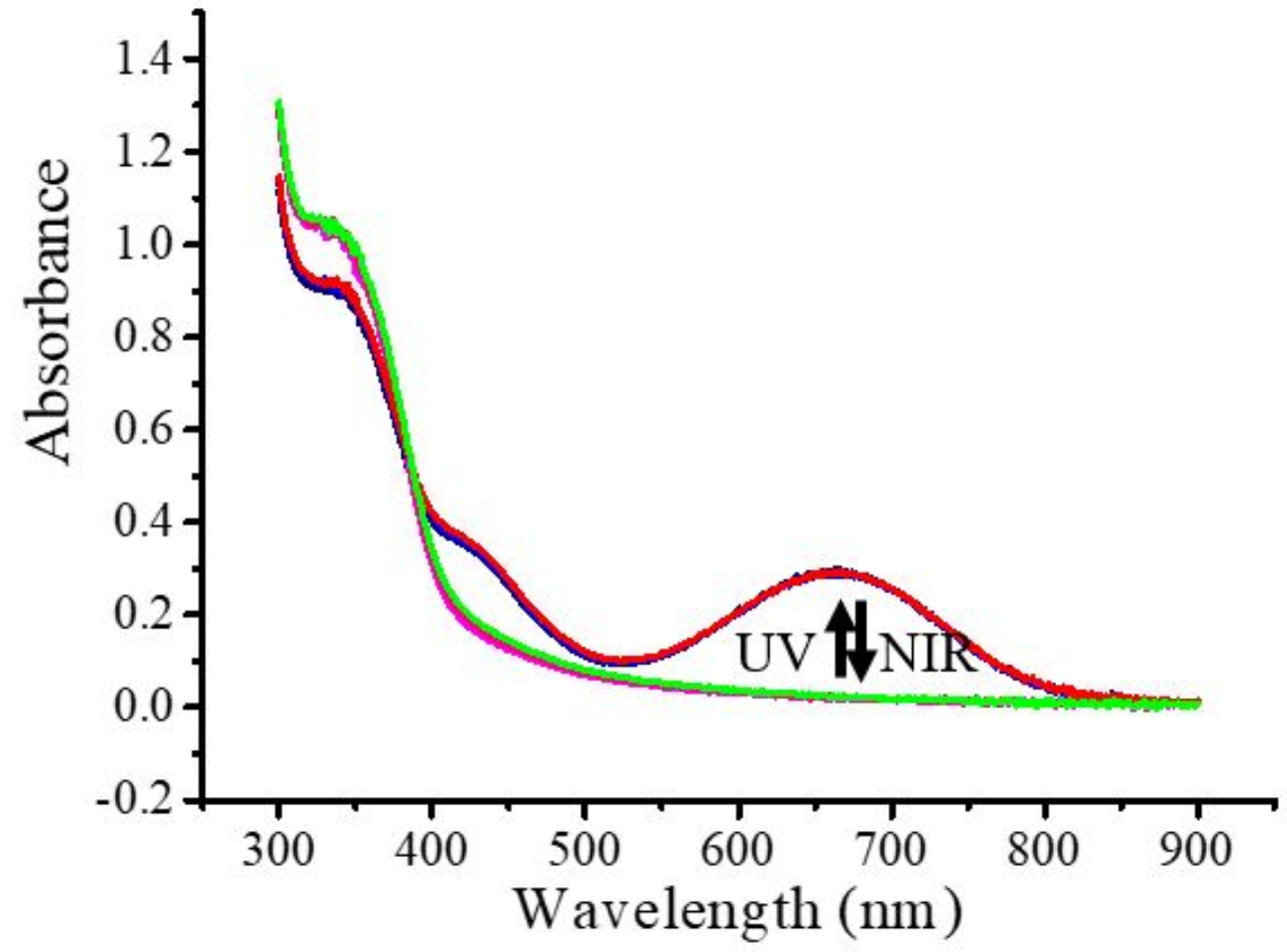

Figure S7. Absorption changes for $2(20 \mu \mathrm{M})$ upon alternating $365 \mathrm{~nm}$ and $760 \mathrm{~nm}$ 
irradiation.in $\mathrm{H}_{2} \mathrm{O}$.

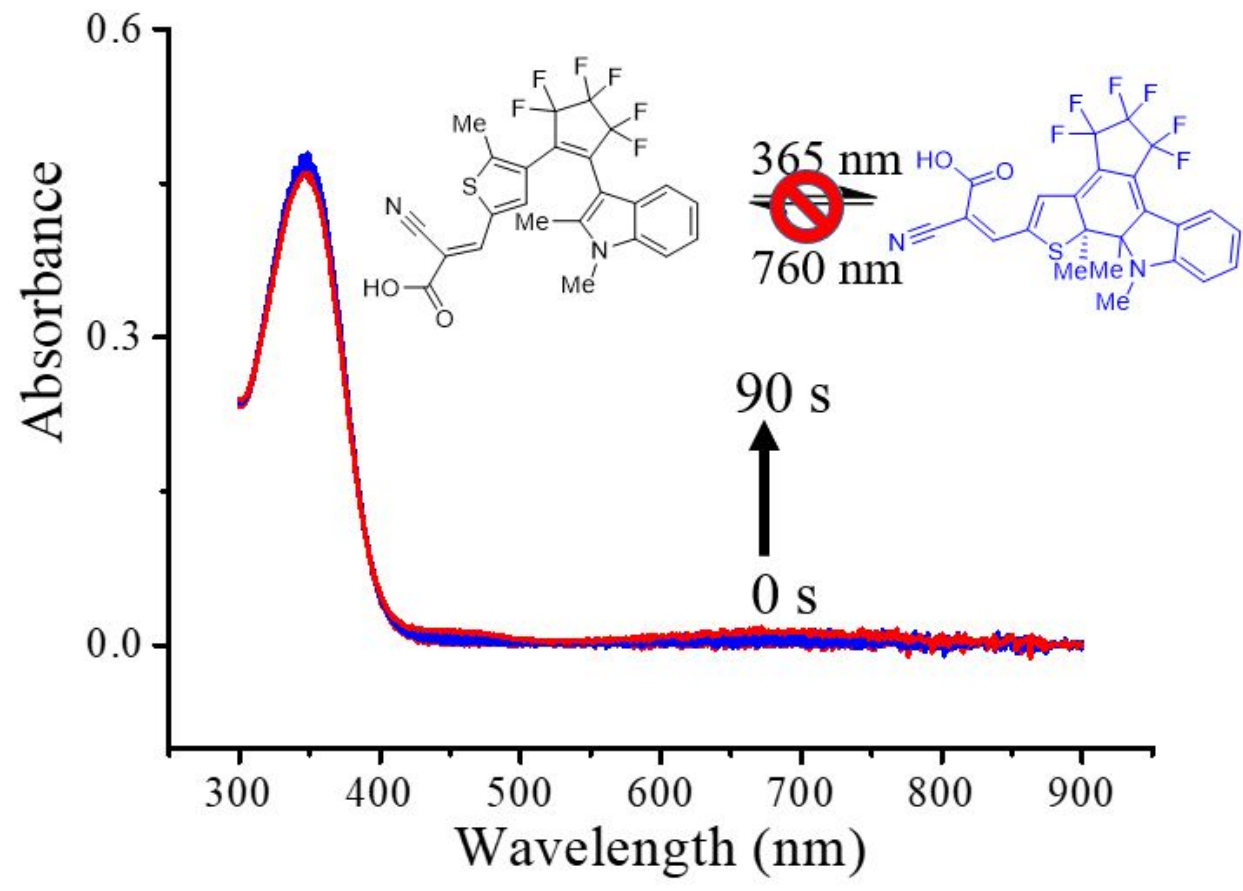

Figure S8. Absorption spectra of $\mathbf{1}(20 \mu \mathrm{M})$ upon exposure to $365 \mathrm{~nm}$ light for 90 seconds in $\mathrm{H}_{2} \mathrm{O}$.

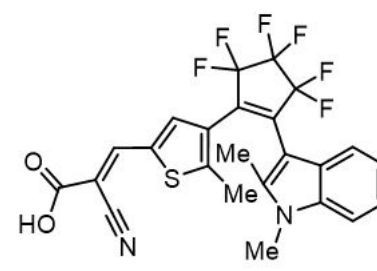

Antiparallel-open form

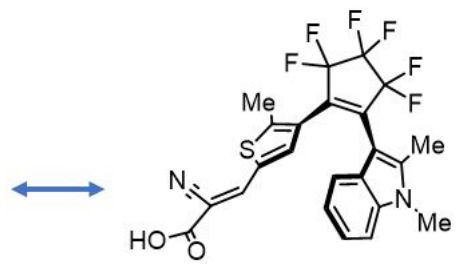

Parallel-open form

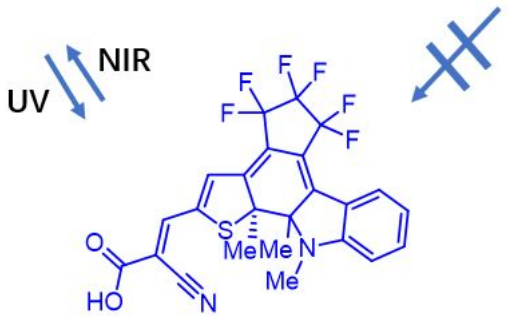

Figure S9 the parallel and antiparallel conformations structure of diarylethene DIA. 


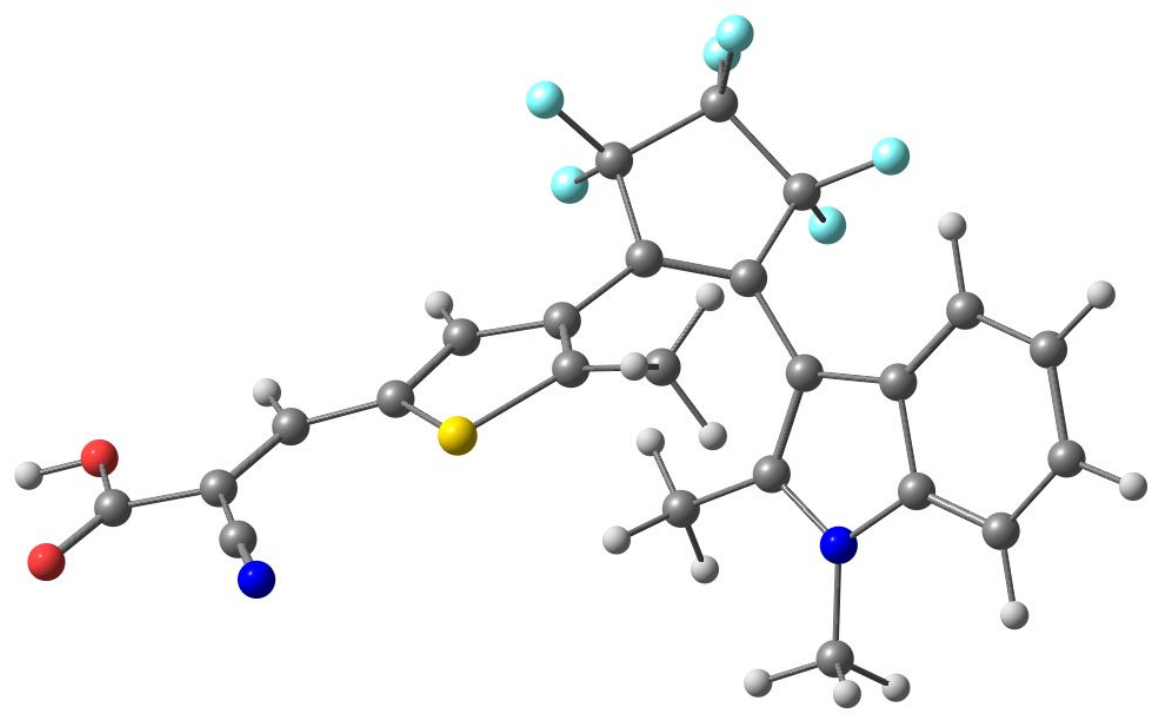

Figure S10. Energy-minimized structure of antiparallel open forms of DIA.

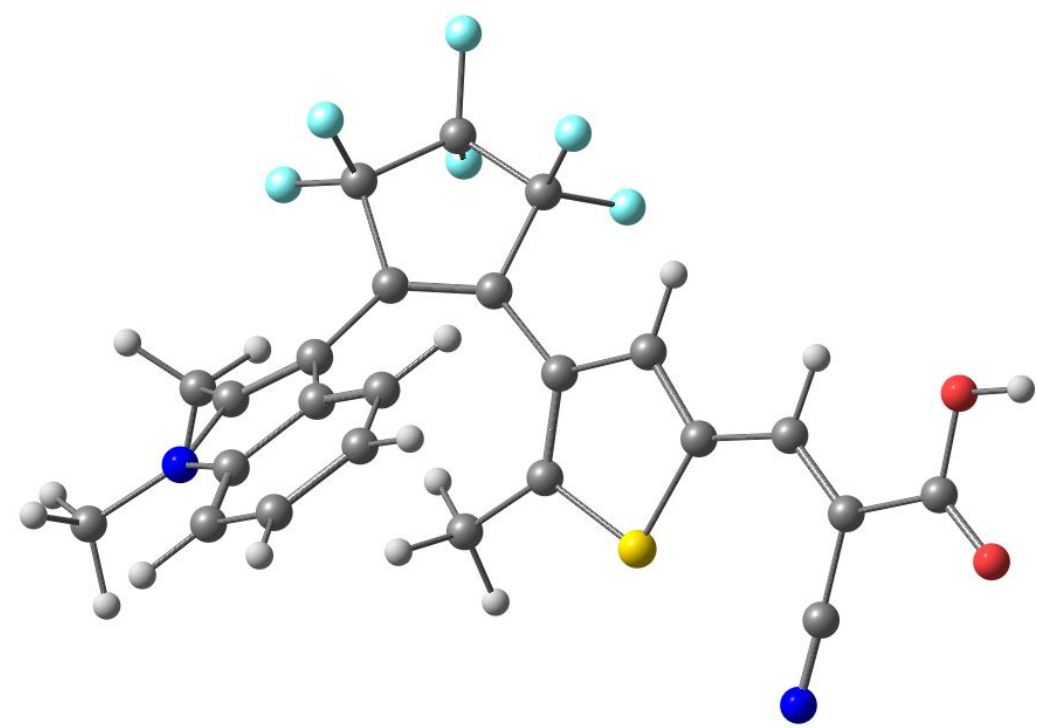

Figure S11. Energy-minimized structure of parallel open forms of DIA. 


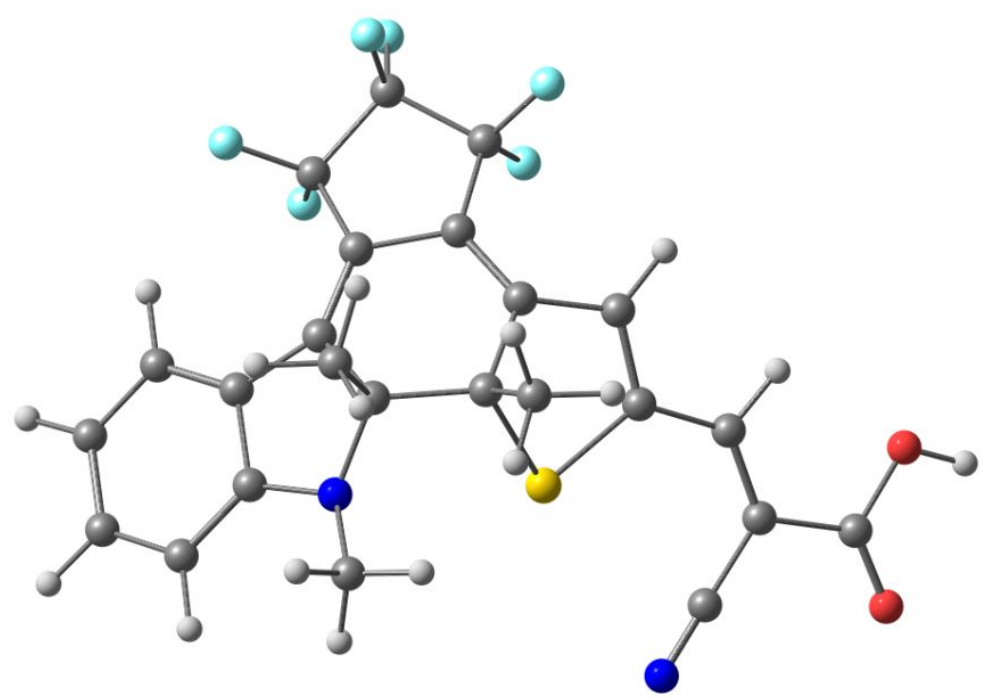

Figure S12. Energy-minimized structure of closed forms of DIA.

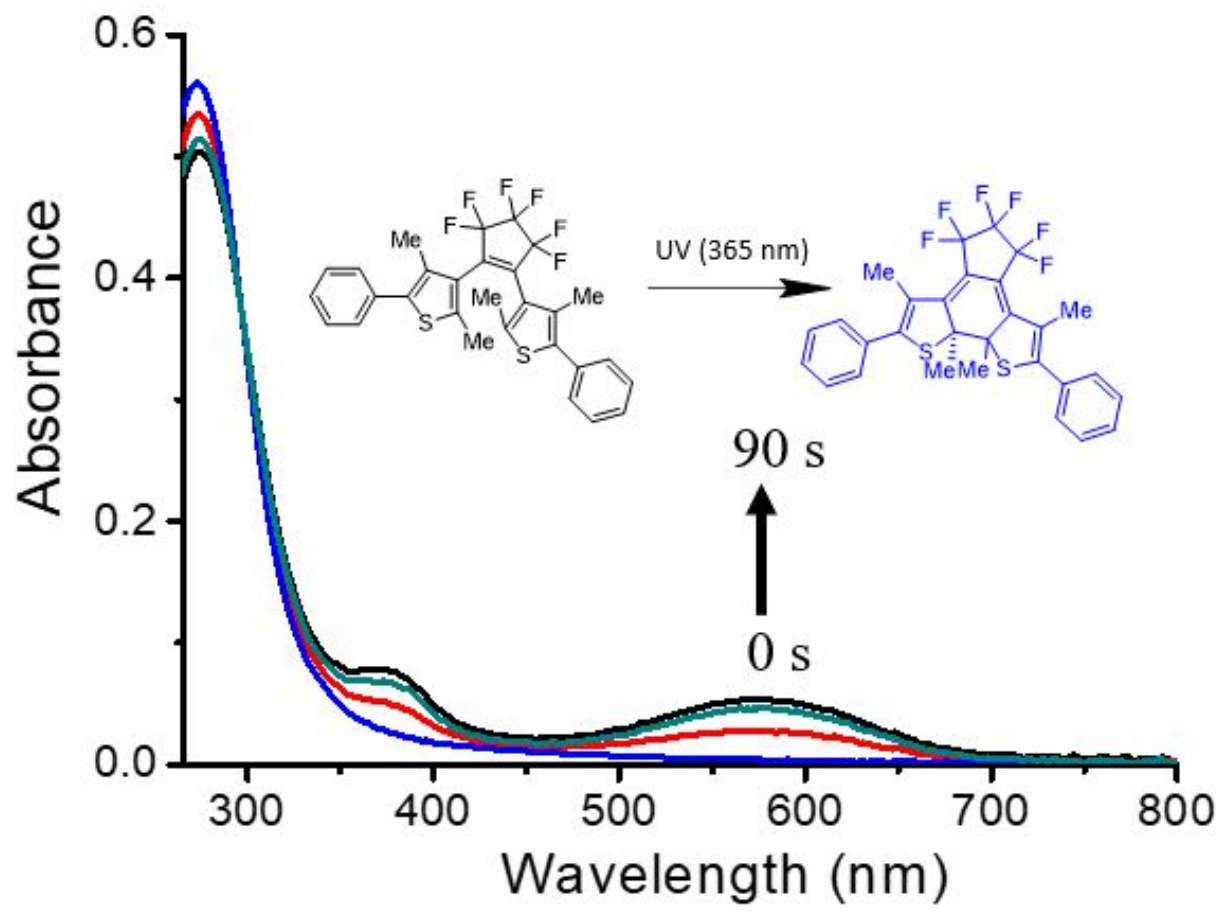

Figure S13 Absorption spectra of 2-Bis(2,4-dimethyl-5-phenyl-3-thienyl)-3,3,4,4, 5,5-hexafluoro-1- cyclopentene (BHC) $(20 \mu \mathrm{M})$ upon exposure to $365 \mathrm{~nm}$ light for 90 seconds in $\mathrm{H}_{2} \mathrm{O}$. 


\section{Parallel-Heme site}

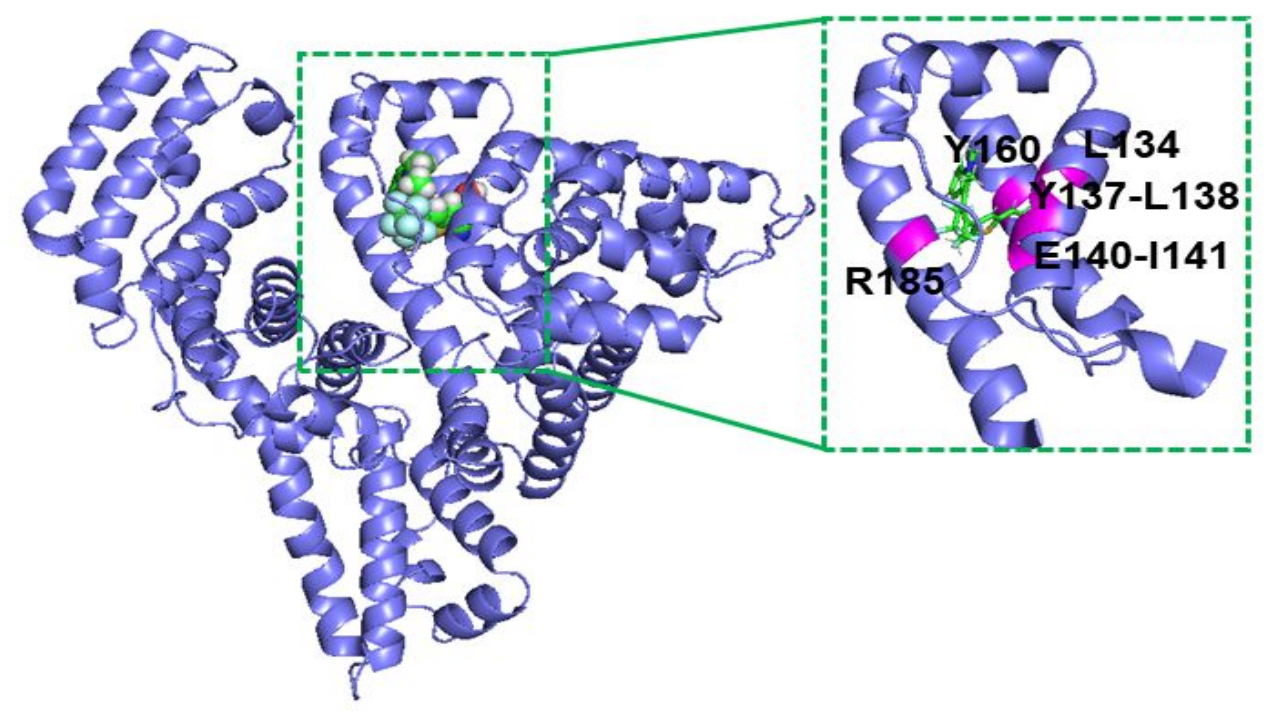

Figure S14. Binding modes of parallel open forms of DIA at the heme binding site of HSA.

\section{Antiparallel-FA7}

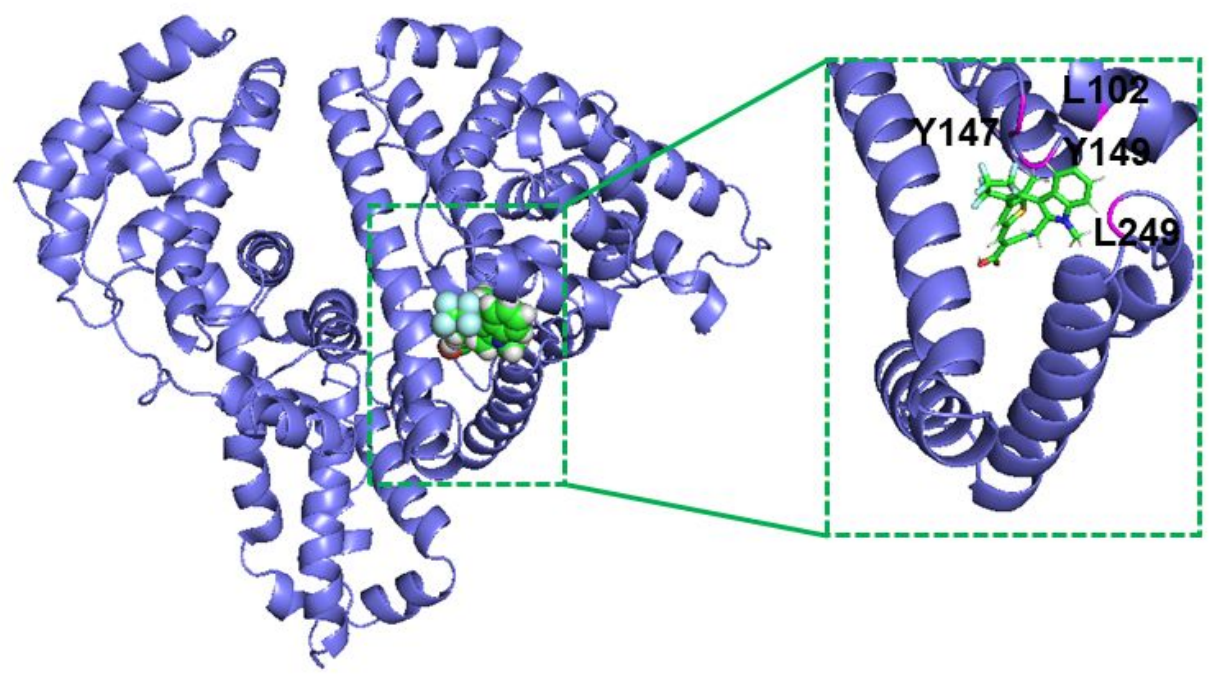

Figure S15. Binding modes of antiparallel open forms of DIA at FA7 regions of HSA. 


\section{Parallel-AF7}

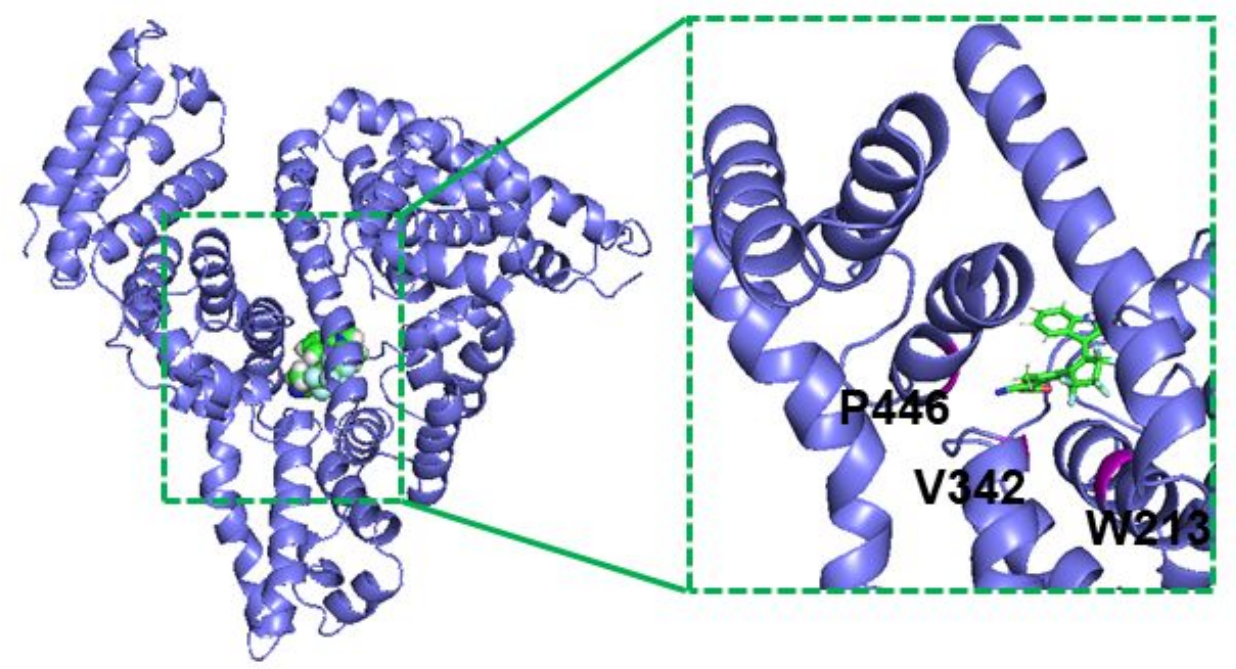

Figure S16. Binding modes of parallel open forms of DIA at FA7 regions of HSA.

\section{Antiparallel-Cleft region}

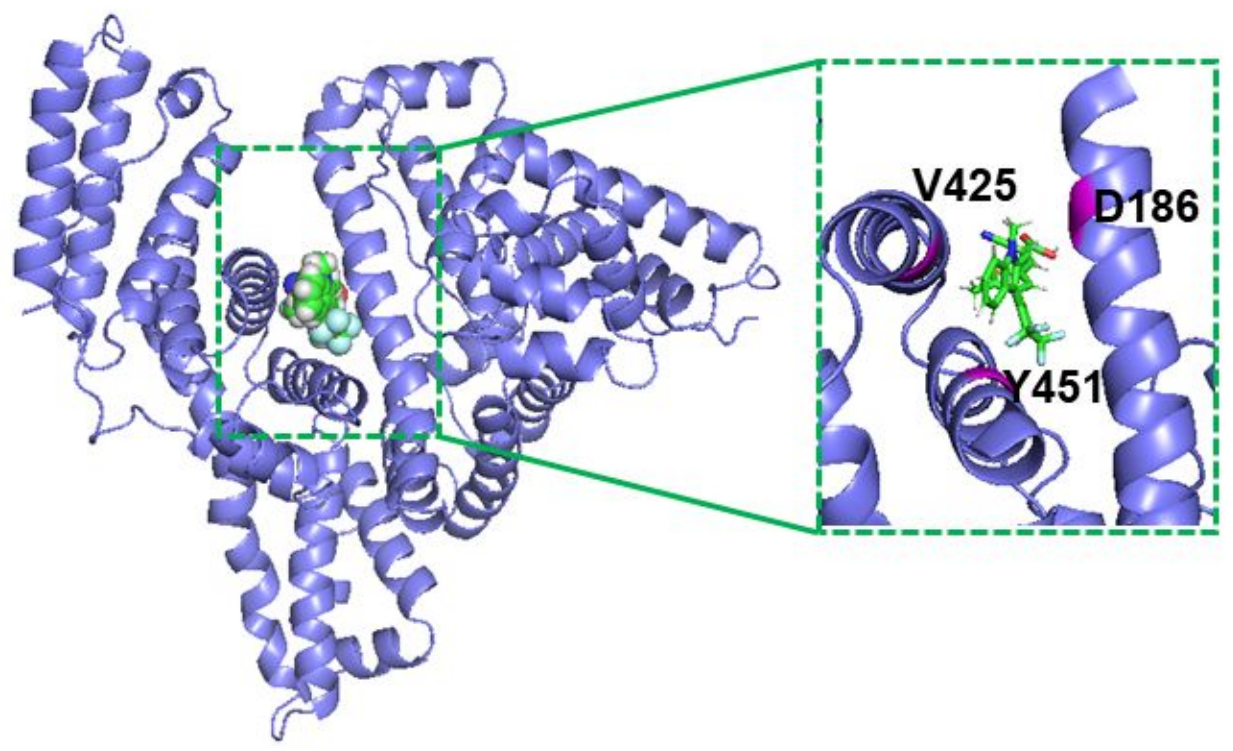

Figure S17. Binding modes of antiparallel open forms of DIA at the Cleft binding site of HSA. 


\section{Parallel-Cleft region}

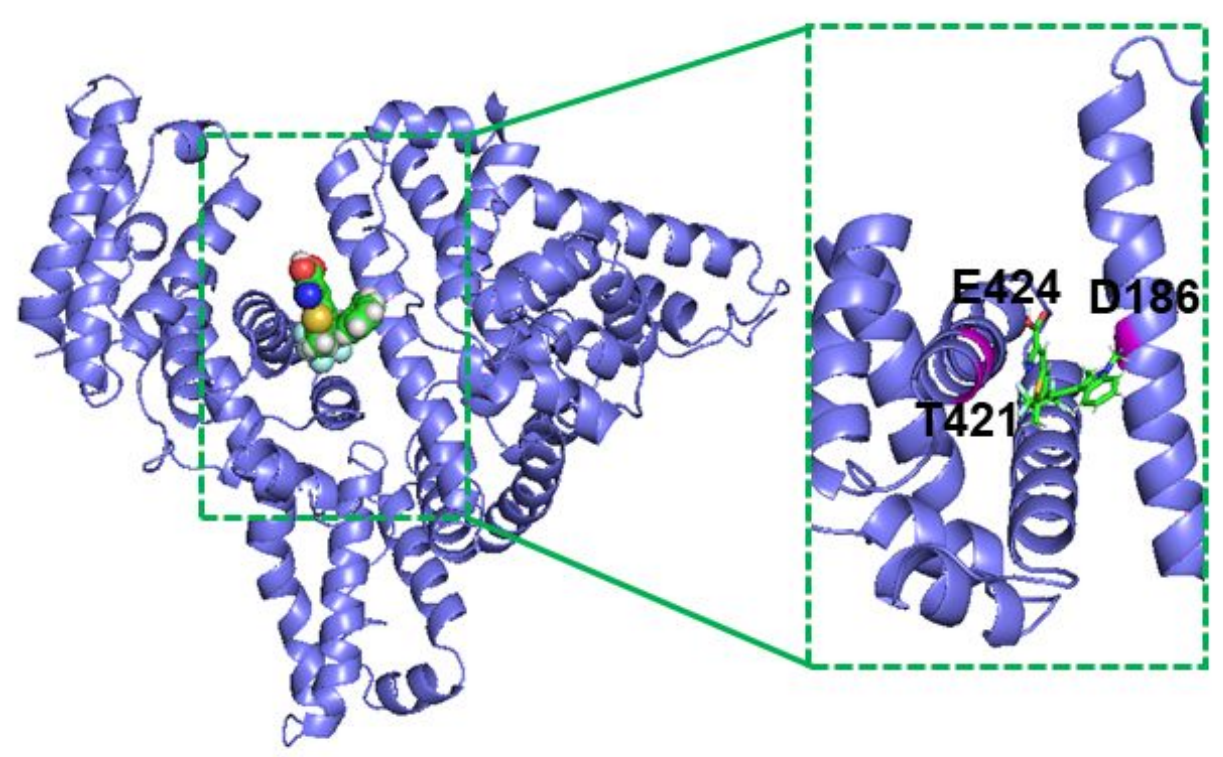

Figure S18. Binding modes of parallel open forms of DIA at the Cleft binding site of HSA.

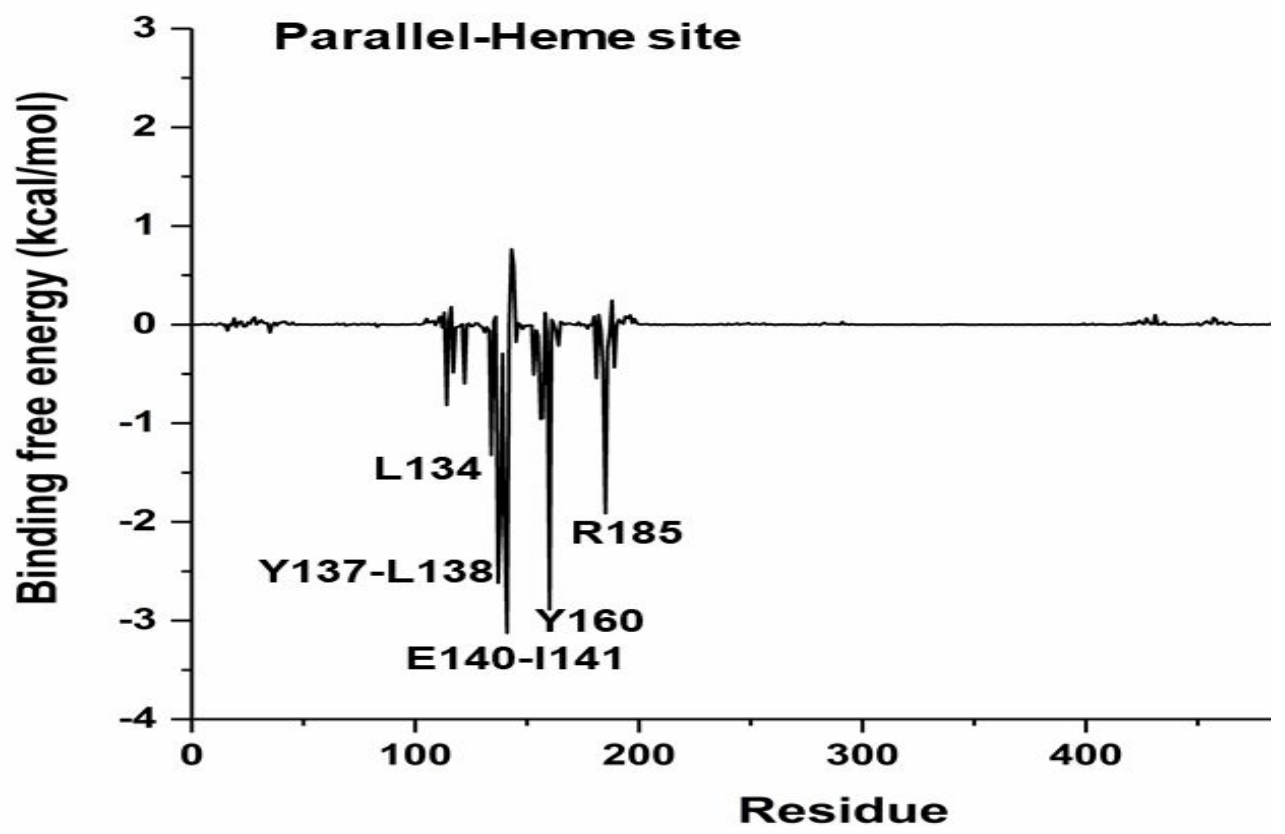

Figure S19. The free energy of binding of the heme binding site of HSA with parallel open forms of DIA. 


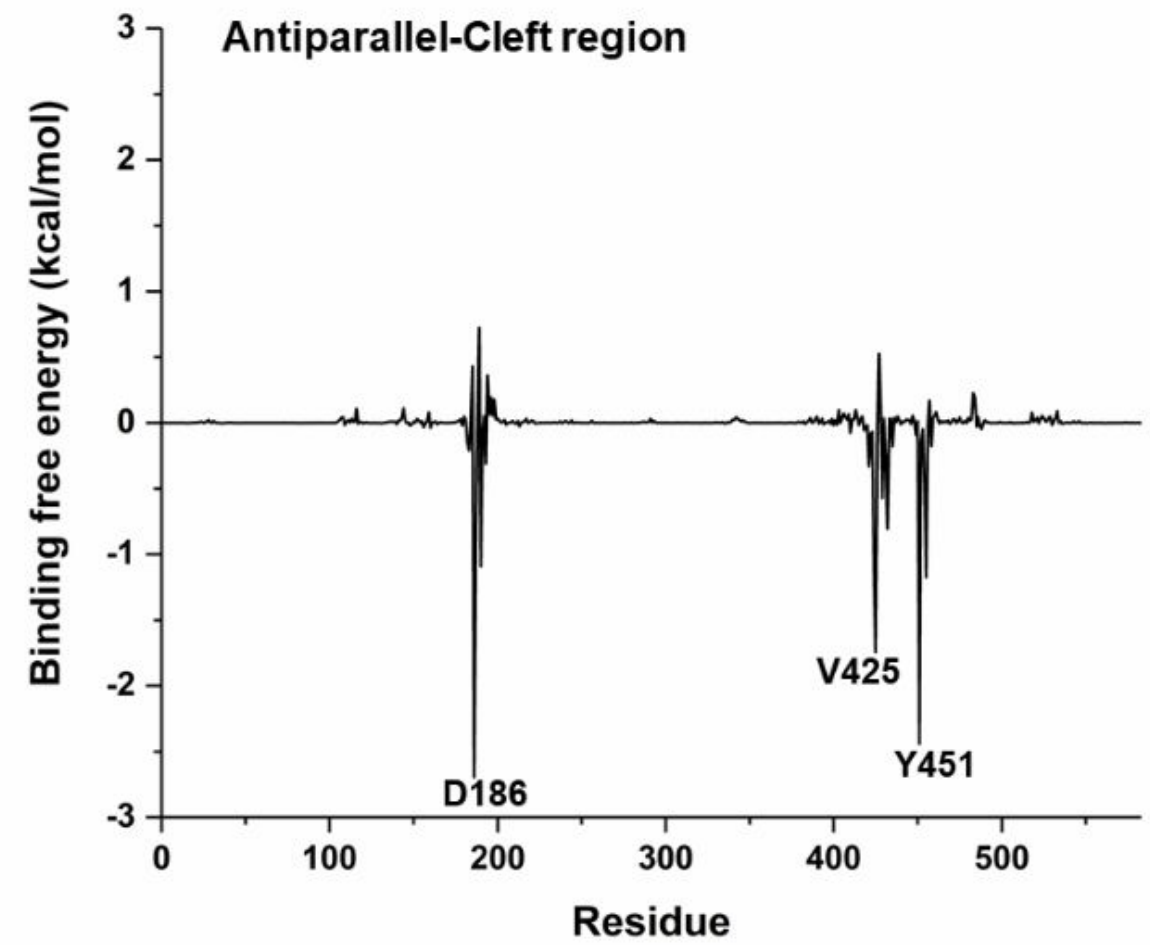

Figure S20. The free energy of binding of the Cleft binding site of HSA with antiparallel open forms of DIA.

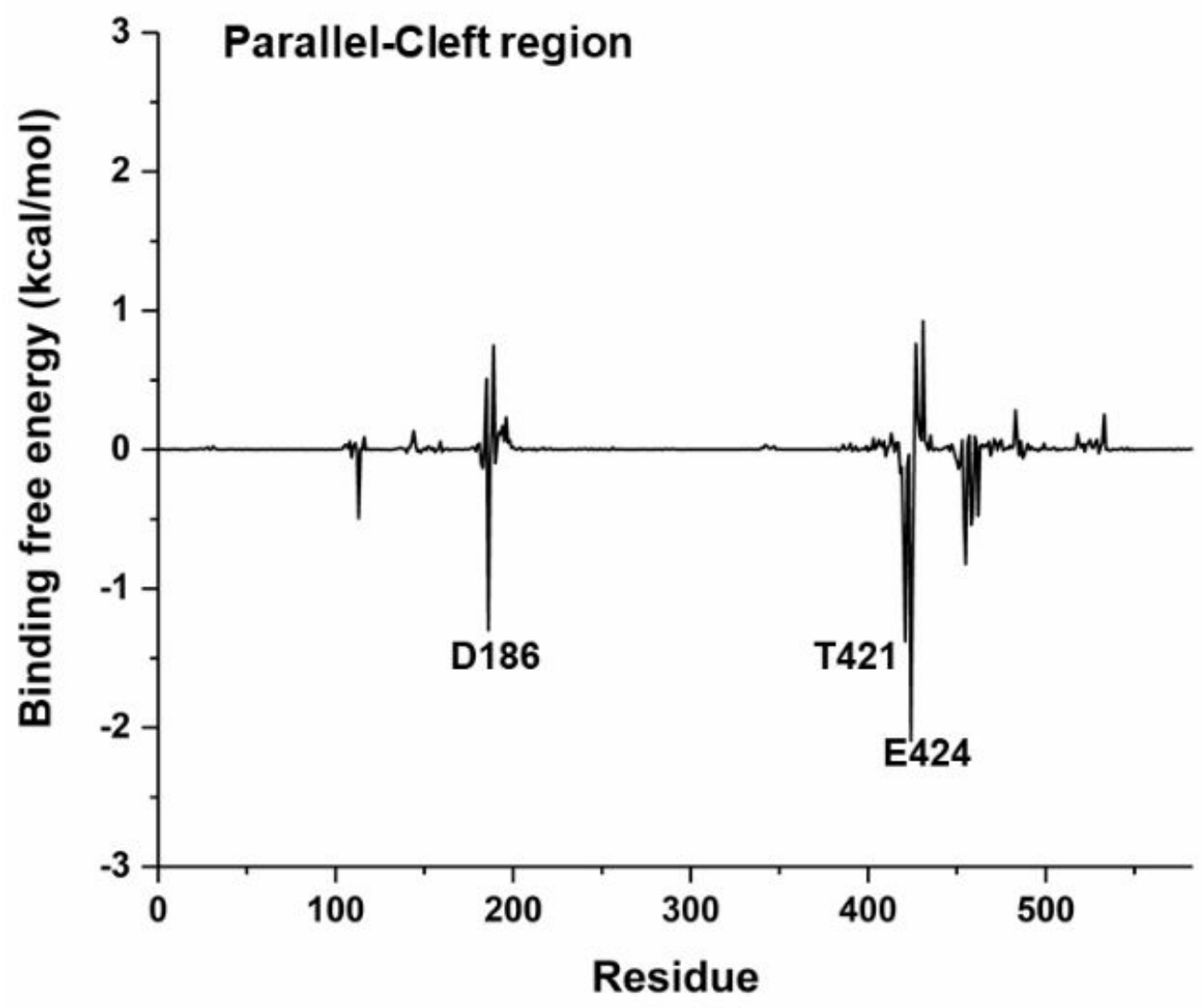

Figure S21. The free energy of binding of the Cleft binding site of HSA with parallel open forms of DIA. 


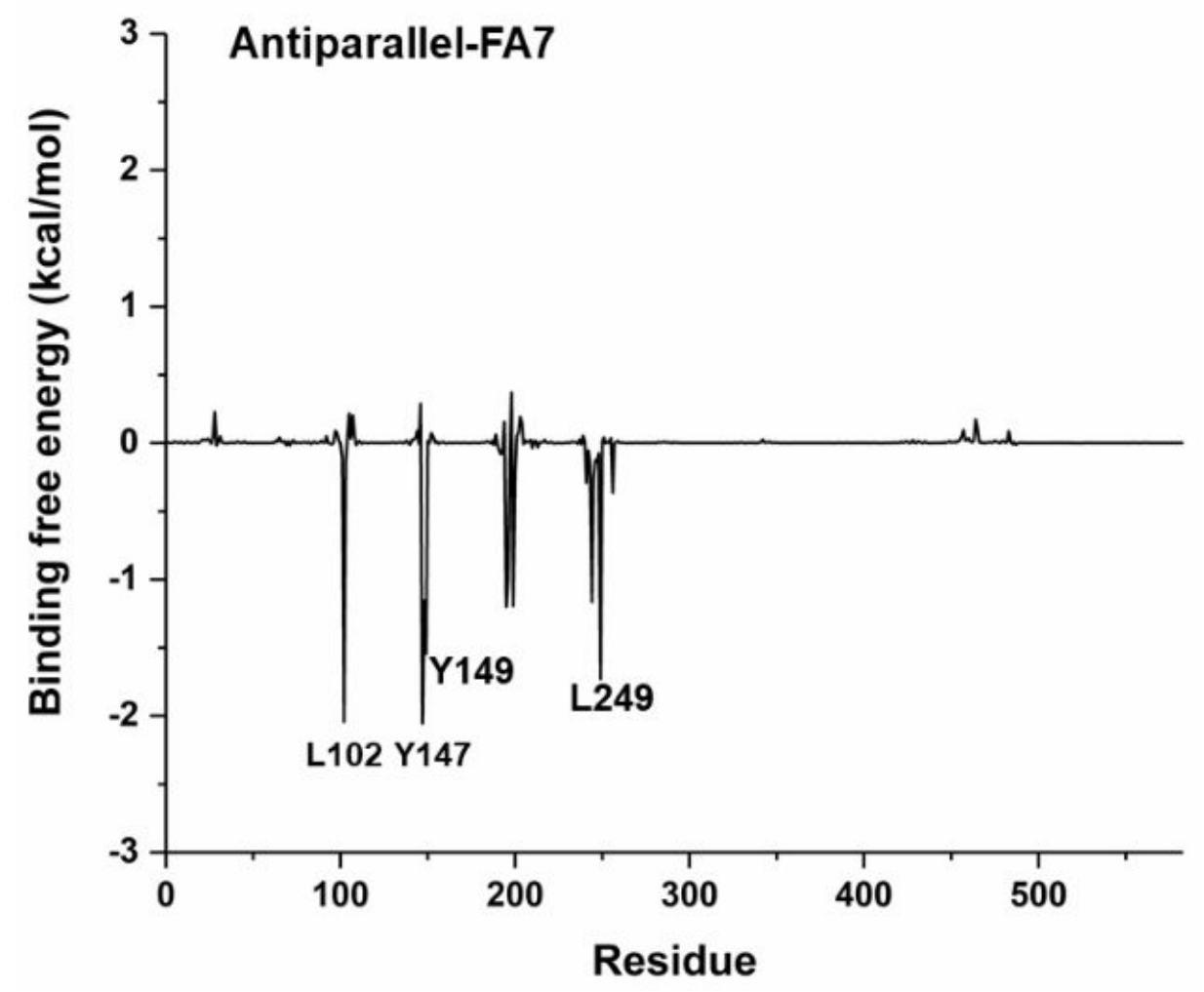

Figure S22. The free energy of binding of FA7 regions of HSA with antiparallel open forms of DIA.

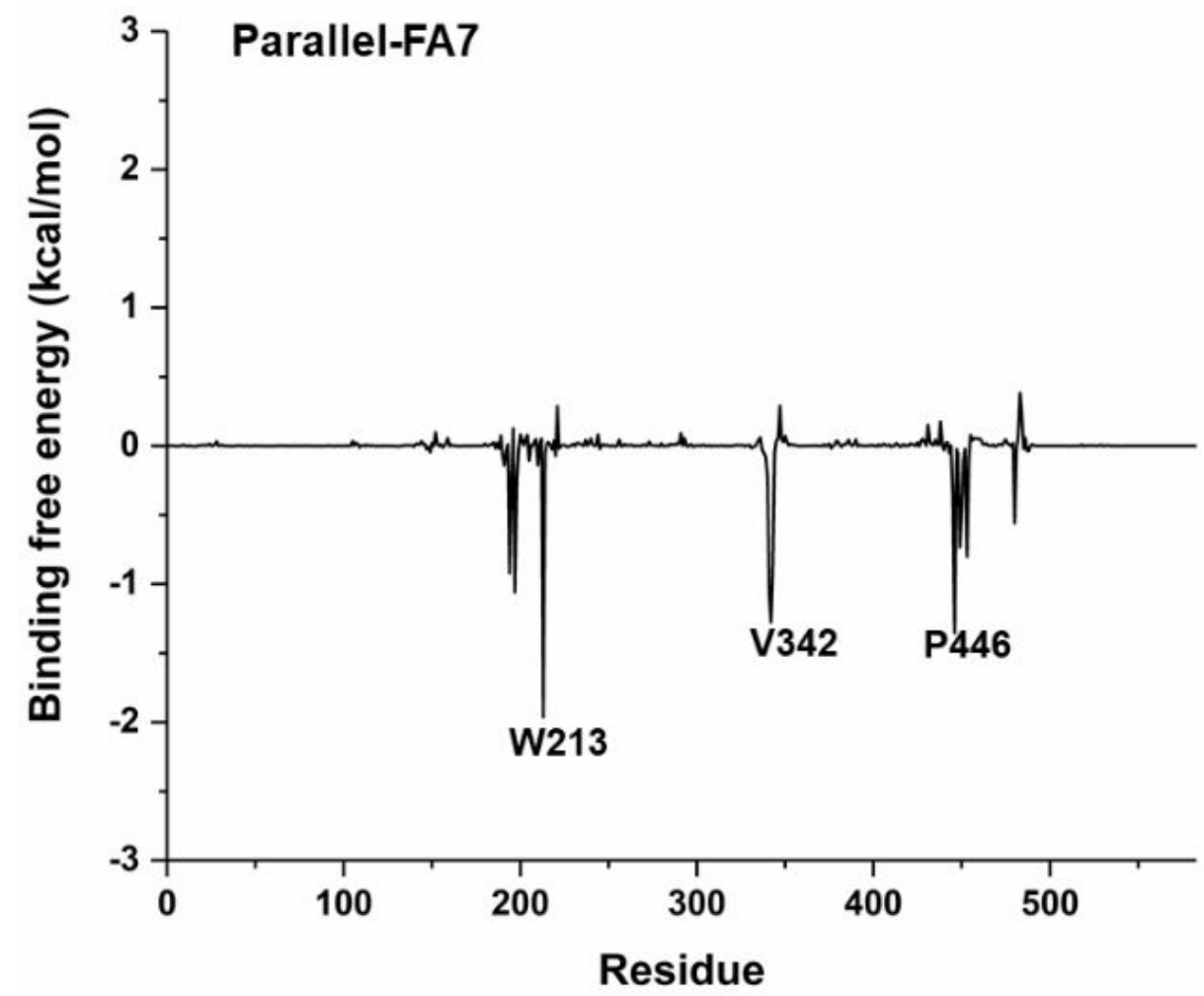

Figure S23. The free energy of binding of FA7 regions of HSA with parallel open forms of DIA. 
Table S1. The binding energy of two open forms of DIA with HSA at different binding sites.

\begin{tabular}{cccc}
\hline Antiparallel & $\begin{array}{c}\text { Binding energy } \\
(\mathrm{kcal} / \mathrm{mol})\end{array}$ & Parallel & $\begin{array}{c}\text { Binding energy } \\
(\mathrm{kcal} / \mathrm{mol})\end{array}$ \\
\hline Heme site & -46.1 & Heme site & -43.8 \\
Cleft region & -35.0 & Cleft region & -22.1 \\
HA7 & -32.4 & HA7 & -31.4 \\
\hline
\end{tabular}

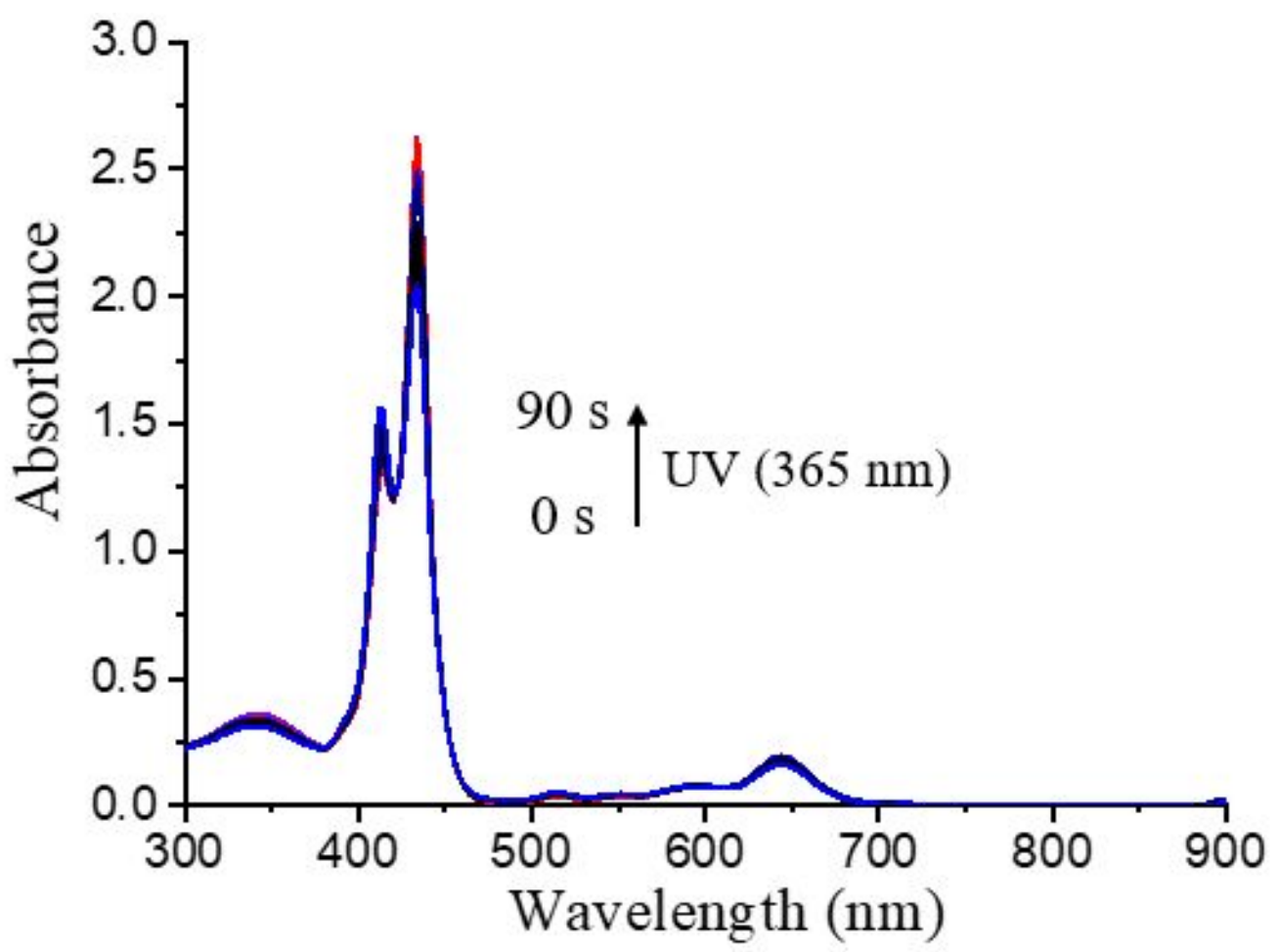

Figure S24. Absorption spectra of DIAporphyrin NPs (30 $\mu \mathrm{M}$ DIA/30 $\mu \mathrm{M}$ porphyrin) upon exposure to $365 \mathrm{~nm}$ light for $1.5 \mathrm{~min}$ in water. 


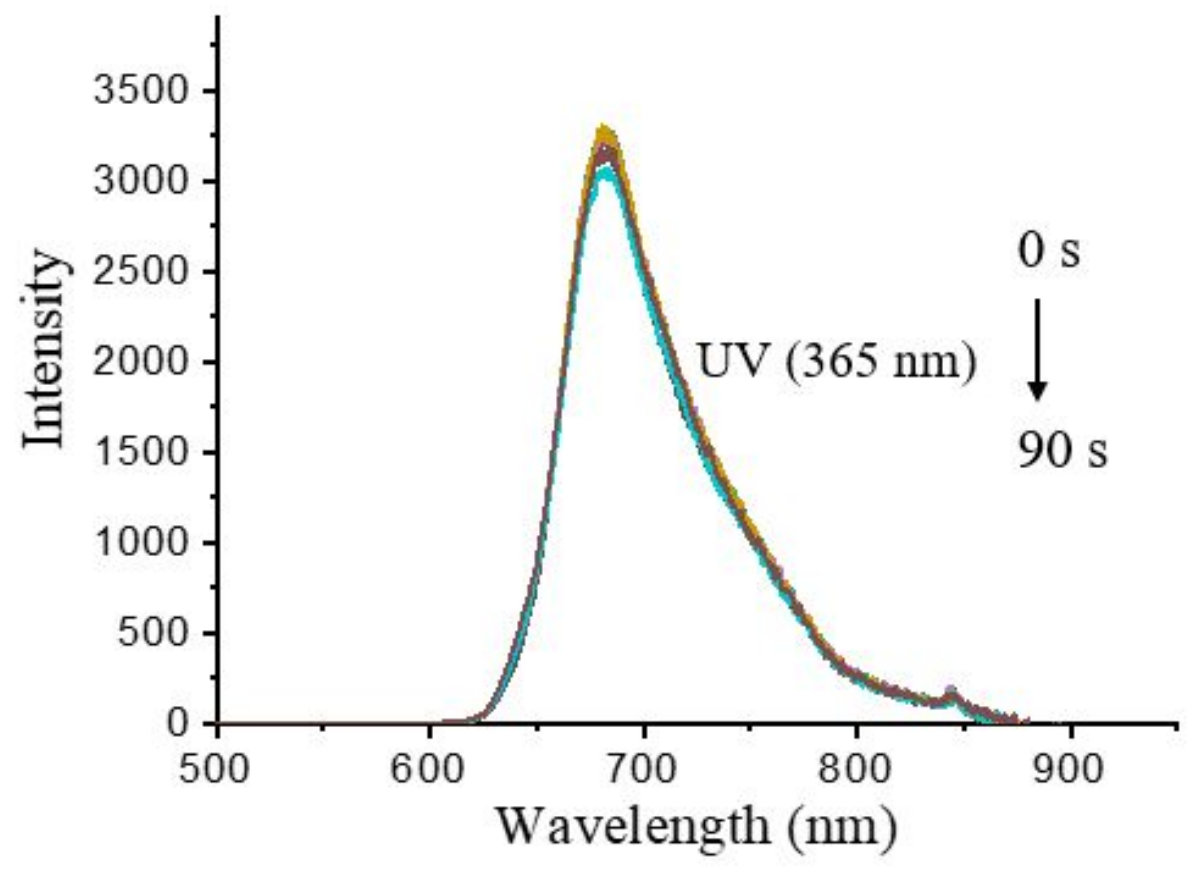

Figure S25. Fluorescence spectra of DIA-porphyrin NPs $(30 \mu \mathrm{M}$ DIA/30 $\mu \mathrm{M}$ porphyrin) upon exposure to $365 \mathrm{~nm}$ light for $1.5 \mathrm{~min}$ in water.
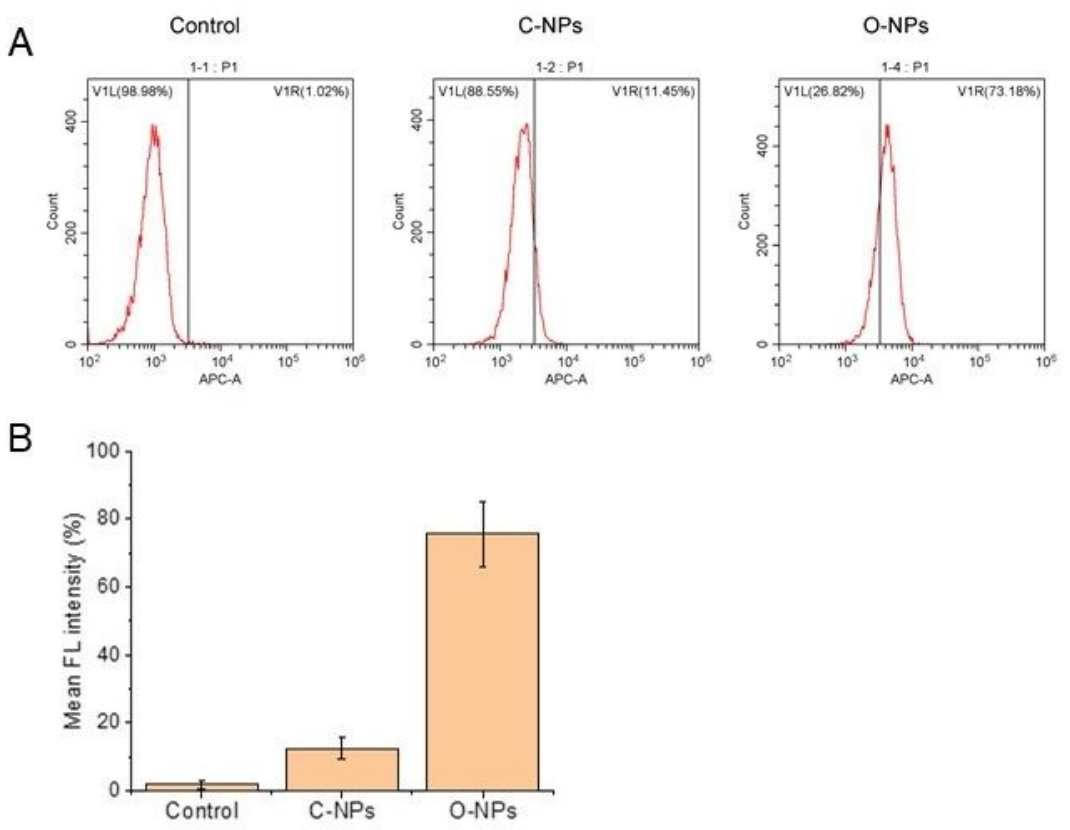

Figure S26. (A) Flow cytometric profiles of 4T1 cells cancer cells upon $1 \mathrm{~h}$ incubation with open-form HSA-DIA-porphyrin NPs and closed-form HSA-DIA-porphyrin NPs. (B) Corresponding quantitative results. 


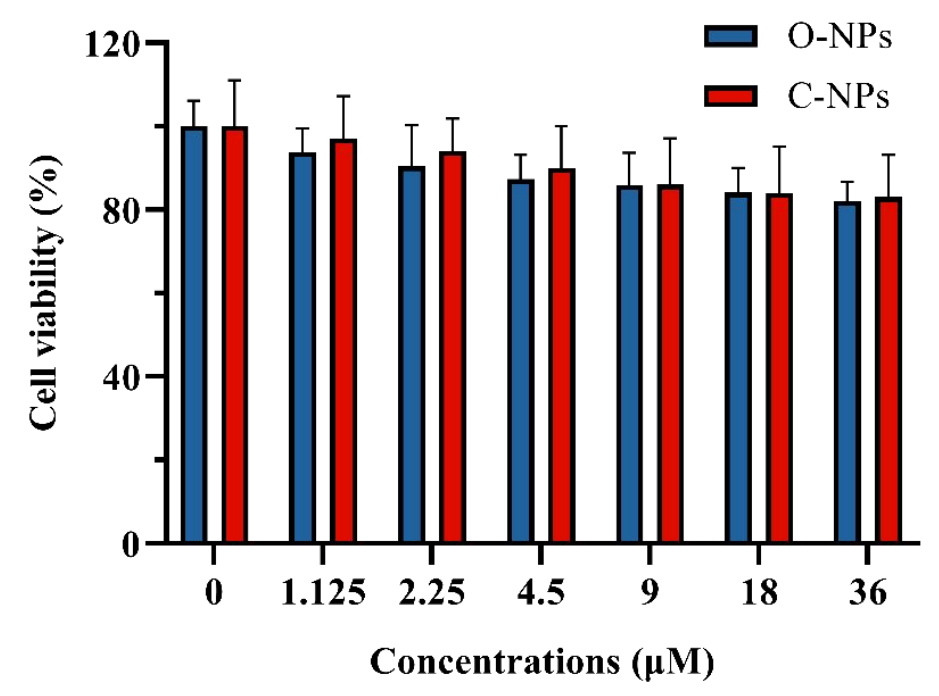

Figure S27. Cell viability of 4T1 cells after co-incubation with various concentrations of open-form HSA-DIA-porphyrin NPs and closed-form HSA-DIA-porphyrin NPs for $24 \mathrm{~h}$.

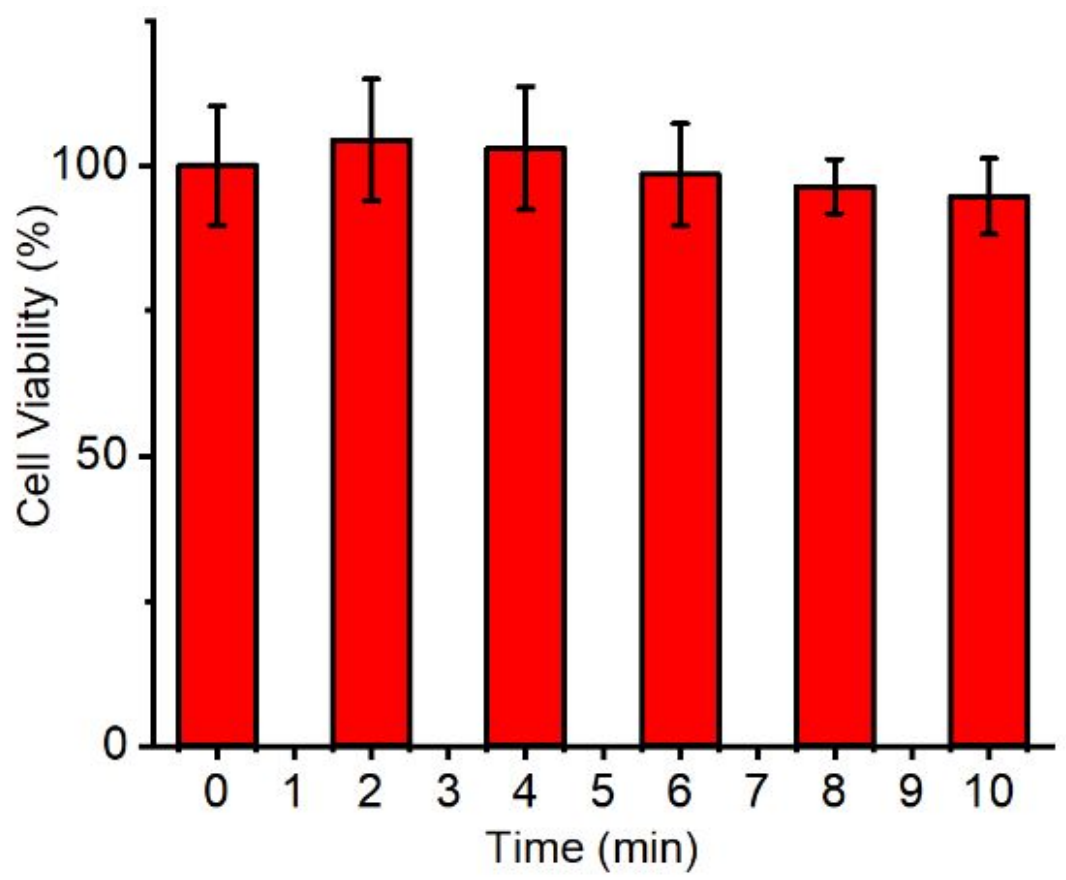

Figure S28. Cell viability of 4T1 cells upon exposure to $365 \mathrm{~nm}$ UV light (portable UV analyzer ZF-5) for 10 minutes. 


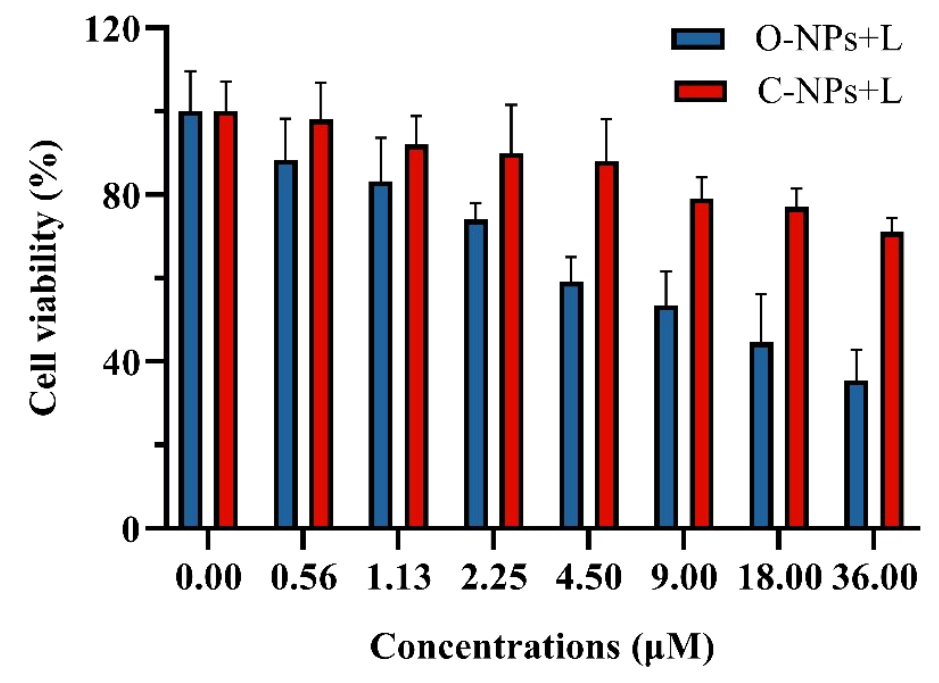

Figure S29. Cell viability of 4T1 cells after co-incubation with various concentrations of open-form HSA-DIA-porphyrin NPs $+420 \mathrm{~nm}\left(100 \mathrm{~mW} / \mathrm{cm}^{2}, 5 \mathrm{~min}\right)$ and closedform HSA-DIA-porphyrin NPs $+420 \mathrm{~nm}\left(100 \mathrm{~mW} / \mathrm{cm}^{2}, 5 \mathrm{~min}\right)$.

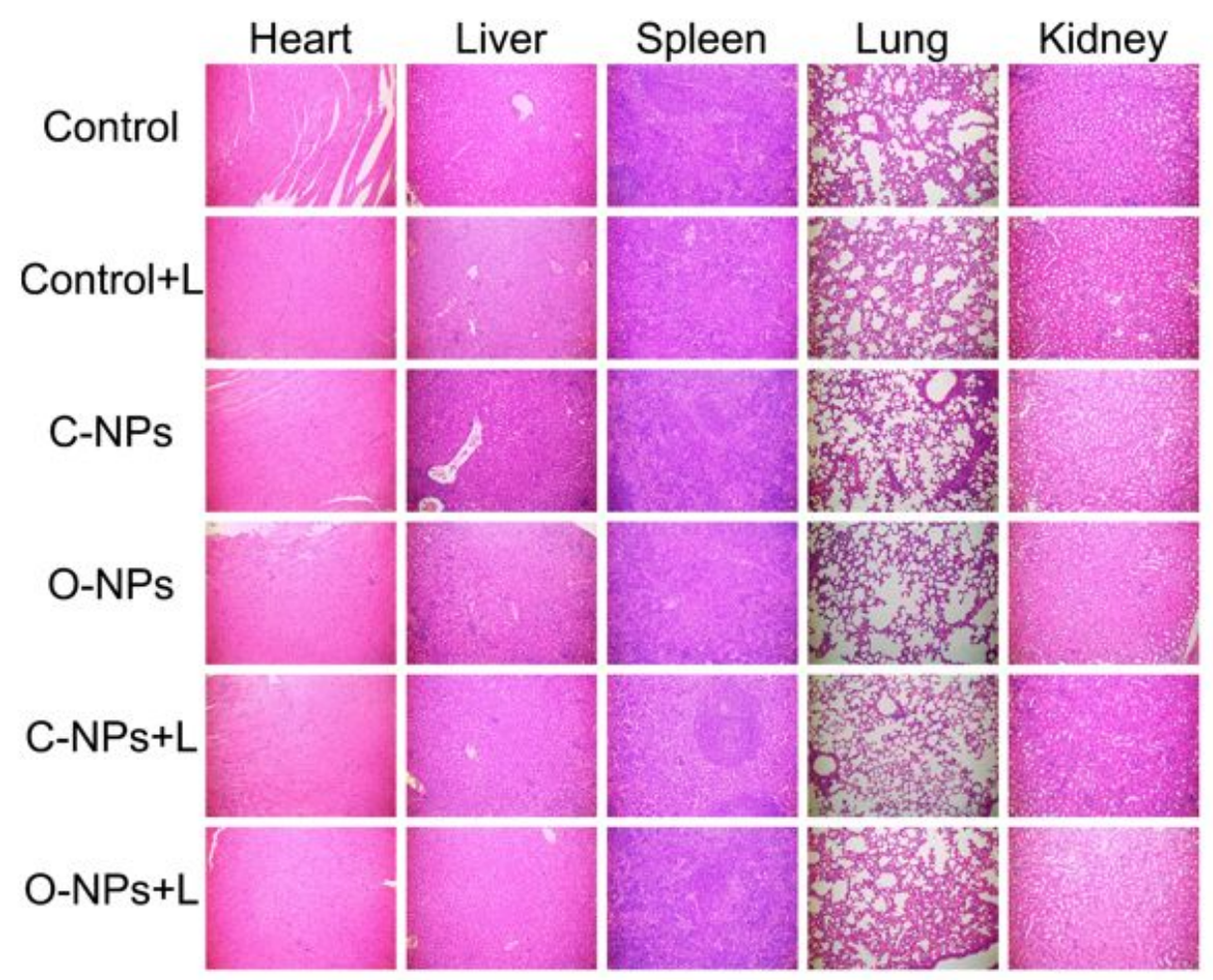

Figure S30. Histological analysis of the organs acquired from mice bearing 4T1 tumors on the 13th day after various treatments as indicated. 


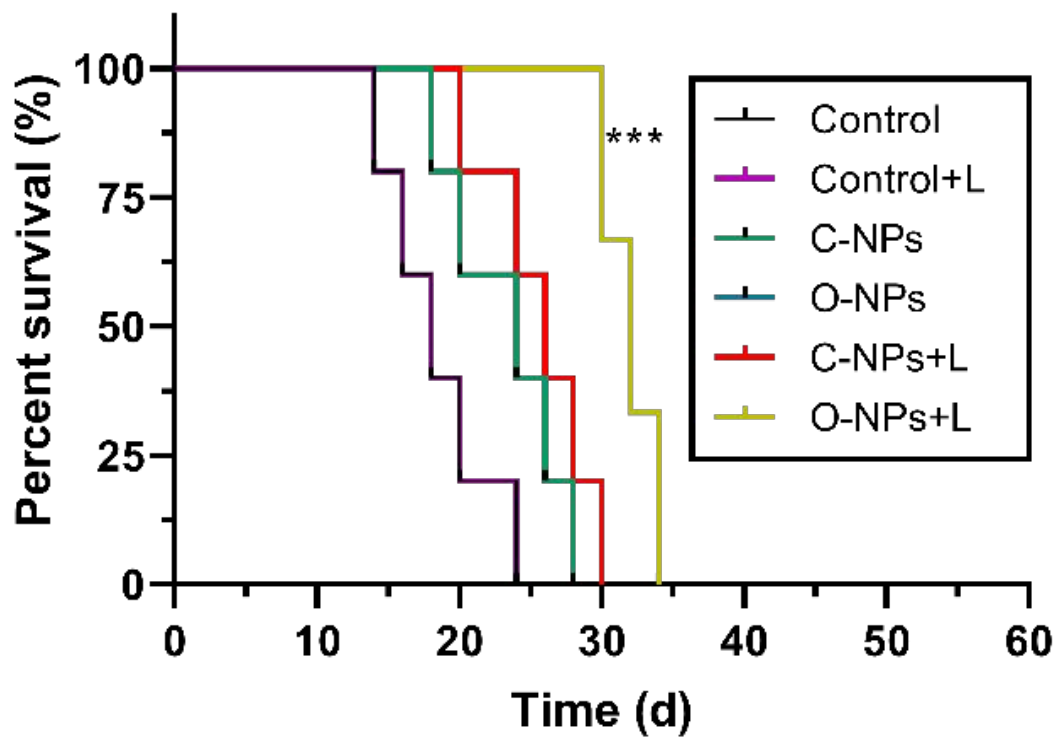

Figure S31. The morbidity-free survival rate of mice after photodynamic therapy.
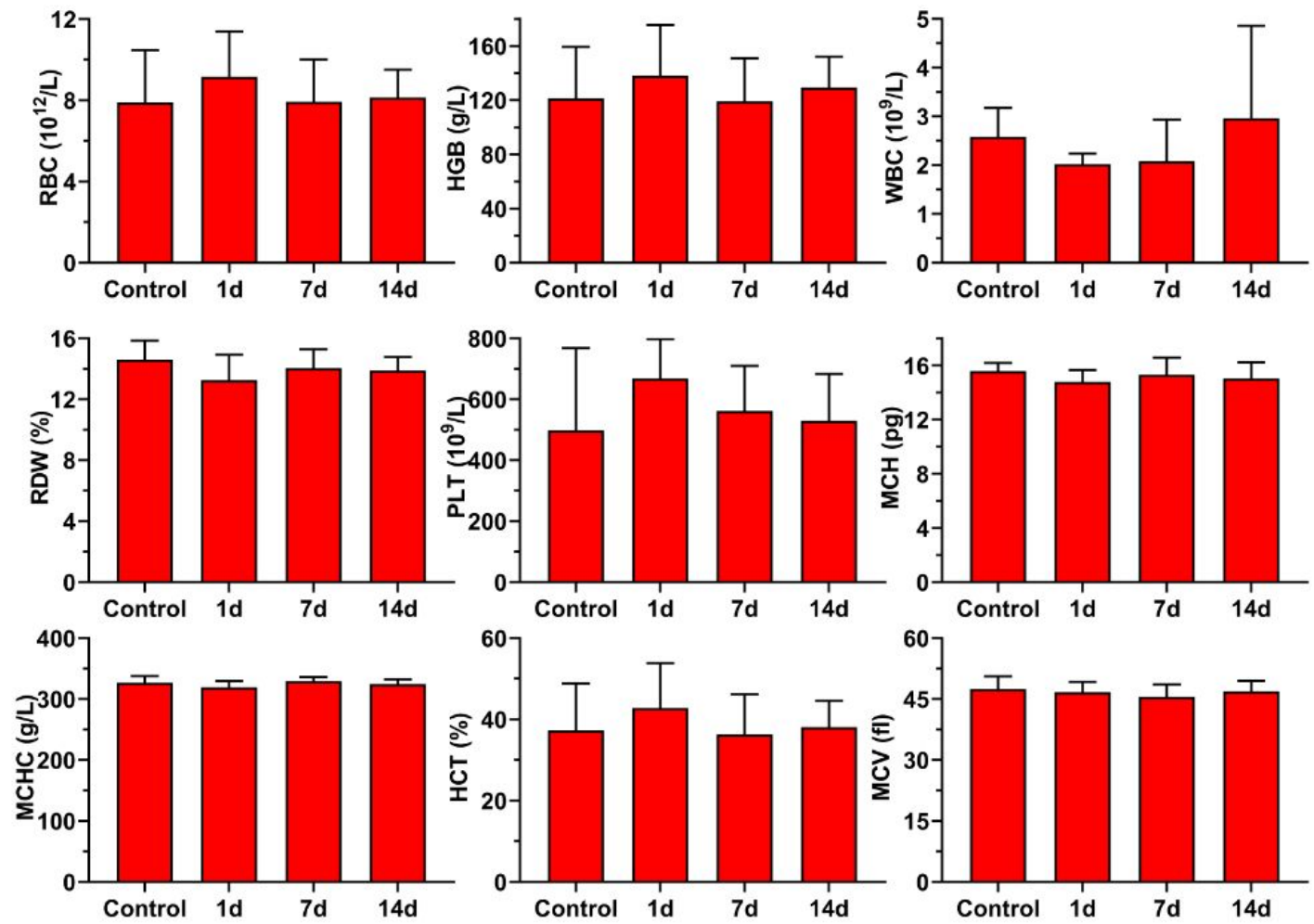

Figure S32. Histograms depicting variations in the routine blood test treated by openform HSA-DIA-porphyrin NPs with different times. 


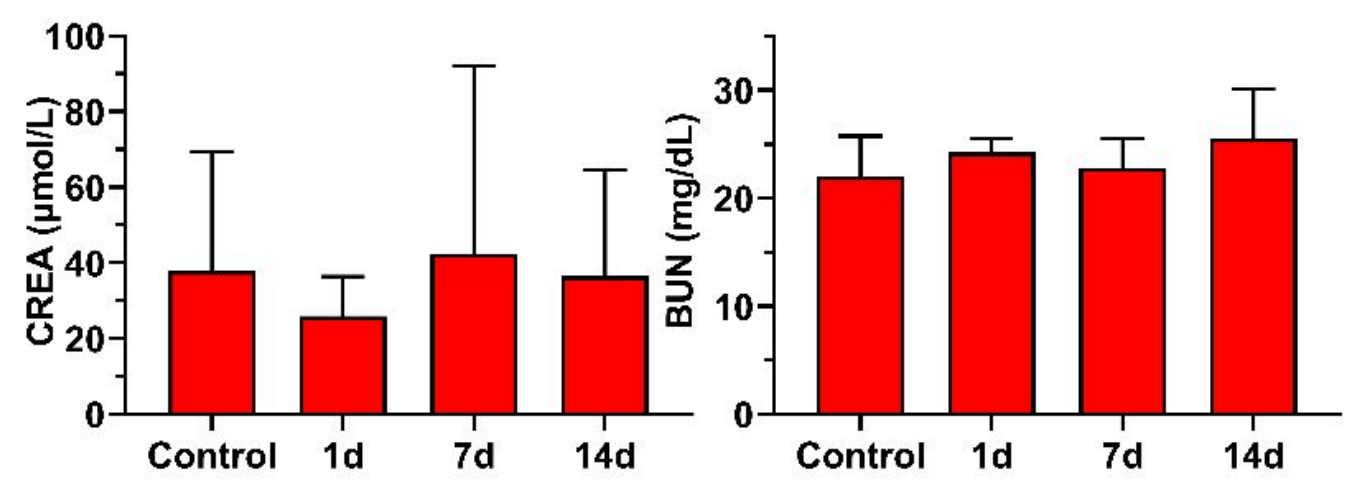

Figure S33. Histograms depicting variations in the kidney functional markers test treated by open-form HSA-DIA-porphyrin NPs with different times.

[1] a) H.-B. Cheng, X. Tan, M.-L. Pang, Eur. J. Org. Chem. 2013, 2013, 7933-7940;

b) H.-B. Cheng, H.-Y. Zhang, Y. Liu, J. Am. Chem. Soc. 2013, 135, 1019010193. 